\begin{tabular}{|c|c|c|c|c|c|}
\hline MUNIBE Antropologia-Arkeologia & $n^{\circ} 71$ & $23-39$ & DONOSTIA & 2020 & ISSN 1132-2217 • eISSN 2172-4555 \\
\hline
\end{tabular}

\title{
La Cova de l'Hort de Cortés-Volcán del Faro (Cullera, Ribera Baixa, País Valenciano). Datos para la discusión de las ocupaciones presolutrenses
}

\author{
Cova de l'Hort de Cortés-Volcán del Faro (Cullera, Ribera Baixa, \\ País Valenciano). Data for the discussion of pre-Solutrean occupations
}

PALABRAS CLAVES: Paleolítico superior, región mediterránea Ibérica, geoarqueología, cronoestratigrafía, industria lítica. GAKO-HITZAK: Goi Paleolitoa, Mediterraneoko Eskualde Iberiarra, geoarkeologia, kronoestratigrafia, industria litikoa. KEY WORDS: Upper Palaeolithic, Iberian Mediterranean region, geoarchaeology, chronostratigraphy, lithic industry.

\section{J. Emili AURA TORTOSA(a), Margarita VADILLO CONESA ${ }^{(a)}$, Carles MIRET I ESTRUCH(b), Carlos C. VERDASCO CEBRIÁN(c), Fernando JIMÉNEZ-BARREDO(d), Jesús F. JORDÁ PARDO(f), Begoña SOLER MAYOR(g)}

\section{RESUMEN}

Los resultados de las excavaciones realizadas entre 1968 y 1984 en la Cova de Hort de Cortés- Volcán del Faro quedaron limitados a identificar materiales solutrenses, magdalenienses y neolíticos-calcolíticos. Una lectura crítica de la Memoria de excavaciones, publicada en 2003 , permitió plantear la posibilidad de la presencia de ocupaciones anteriores, posiblemente gravetienses. En 2018 se iniciaron nuevos trabajos en el yacimiento, dentro de un proyecto que pretende recuperar información a partir de los cortes de las antiguas excavaciones. Los datos obtenidos en el área más externa (corte frontal posterior, cuadrícula O4) han permitido retomar la discusión sobre la existencia de los niveles presolutrenses. Los primeros resultados, sobre los trabajos realizados en el perímetro del sector A de las antiguas excavaciones, así como los datos geoaqueológicos, radiocarbónicos e industriales plantean una serie de alternativas sobre la formación y conservación del depósito que supone un punto de partida para la comprensión de un yacimiento complejo.

\section{LABURPENA}

1968 eta 1984 artean Cova de Hort de Cortés- Volcán del Faron egindako indusketen emaitzak Solutre aldiko, Madeleine aldiko eta Neolito-Kalkolito aldiko materialak identifikatzera mugatu ziren. 2003an indusketa-memoriaren irakurketa kritiko bat argitaratu zen, eta irakurketa hark lehenagoko okupazioen (beharbada okupazio Gravettiarrak) presentzia mahai gainean jartzeko aukera eman zuen. 2018an lan berriak hasi zituzten aztarnategian, garai bateko indusketen ebakiduretatik abiatuta informazioa berreskuratzea helburu duen proiektu baten baitan. Kanpoaldeko eremuan jasotako datuek (atzealdeko ebakidura frontala, O4 laukia) Solutre aldiaren aurreko mailak daudenaren inguruko eztabaidari berriro ekitea ahalbidetu dute. Garai bateko indusketetako A sektorearen perimetroan egindako lanen gaineko emaitzek eta datu geoarkeologikoek, erradiokarbonikoek eta industrialek metakinaren eratzearen eta kontserbazioaren gaineko hainbat alternatiba jarri dituzte mahai gainean, eta hori aztarnategi konplexu bat ulertzeko abiapuntua da.

\section{ABSTRACT}

The excavation of the Volcán del Faro site (Cullera, Valencia) did not live up to the expectations created after the discovery of the perforated staff. The prospect of a new Palaeolithic sequence, close to that of Parpalló (Gandia, Valencia), brought with it the possibility of obtaining new palaeoenvironmental, chronostratigraphic and archaeological data. However, the results of excavations carried out between 1968 and 1984 only identified Solutrean, Magdalenian and Neolithic - Chalcolithic materials. No chronostratigraphic data were obtained and the description of lithic and osseous industries was based on subjective considerations. Therefore, the repeated mention of Solutrean morphotypes, which were of Magdalenian chronology according to their excavator, could not be compared with any other site. Likewise, it was not possible to obtain any radiocarbon dates, largely due to poor collagen conservation, or lithostratigraphic data or a description of lithic and osseous industries that could be compared at a regional level. The only palaeoenvironmental and palaeoeconomic data were incorporated into the study of mammalian fauna carried out by I. Davidson, a reference work in studies of the Palaeolithic economy in the Spanish Mediterranean region.

\footnotetext{
(a) PREMEDOC, Dept. de Prehistòria, Arqueologia i Hia. Antiga, Universitat de València, Avda. Blasco Ibañez 28, E-46010, València, Spain. J.Emili. Aura@uv.es.

(b) Investigador independiente.

(c) Estudios de Afección Patrimonial, Calle Begoña, 3. BL A, PTA. 1-1, L’Eliana, 46183 Valencia, Spain.

(d) Centro Nacional de Investigación sobre la Evolución Humana, Burgos.

(f) Laboratorio de Estudios Paleolíticos, Departamento de Prehistoria y Arqueología, Facultad de Geografía e Historia, Universidad Nacional de Educación a Distancia, Paseo Senda del Rey 7, E- 28040, Madrid, Spain.

(g) Museu Valencià de Prehistòria, Carrer de la Corona, 36, 46003 Valencia, Spain
} 
Solutrean, Badegoulian and Magdalenian materials were identified from a critical reading of the excavation report, which was published in 2003, suggesting the possibility of earlier, possibly Gravettian occupations. However, this hypothesis was not based on lithostratigraphic or radiocarbon data.

In 2018, further work was undertaken at the site as part of a project seeking to gain information from the stratigraphic sections of the old excavations. The data obtained from the outermost area (posterior frontal cross-section, O4 square) provide some initial points for discussion regarding the existence of pre-Solutrean levels at HC-VF, but this time based on geoarchaeological, chronological and archaeological data. At the same time, the topographic position of the data obtained in relation to the old excavations presents a number of alternatives regarding the formation and preservation of the remains, representing a starting point for understanding this complex site.

\section{INTRODUCCIÓN}

Los yacimientos excavados hace unas décadas suelen acumular en los museos una gran cantidad de materiales arqueológicos y bioarqueológicos, pero cuentan con un nivel de contextualización geoarqueológica, arqueoestratigráfica y cronológica desigual. Este es el caso del yacimiento de la Cova de l'Hort de Cortés-Volcán del Faro (HC-VF a partir de ahora), pues a pesar de contar con la publicación de una memoria de las excavaciones relativamente reciente (Aparicio, 2003), carece de una documentación arqueoestratigráfica y cronológica sobre la secuencia y características de las ocupaciones humanas. La publicación del bastón perforado, considerado magdaleniense - pero asociado a materiales solutrenses - y la falta de estudios básicos (estratigrafía, cronología, bioarqueología e industrias) relegó su secuencia a la anécdota de una pieza singular en su momento. La necesidad de conocer el estado del yacimiento y de incorporarlo a los temas de discusión actual del Paleolítico del sur de Europa (Aura Tortosa, 1995, 2007; Aura Tortosa et al., 2012), ha sido el punto de partida del proyecto de investigación iniciado en 2018.

Cincuenta años después de la primera publicación sobre la cueva paleolítica del Volcán del Faro (Fletcher y Aparicio, 1969), presentamos en este trabajo nuevos datos para la discusión sobre la existencia de niveles presolutrenses en el yacimiento. Esta cuestión ya fue planteada en un trabajo dedicado a analizar la información estratigráfica recogida en la memoria y al estudio de los elementos de adorno. Allí se proponía que, por debajo de las capas con azagayas monobiseladas, puntas de escotadura, piezas bifaciales de retoque plano y de cara plana, existían suficientes materiales diagnósticos como para plantear la existencia de ocupaciones gravetienses, al menos en el sector A (Soler et al., 2013).

Los datos obtenidos en 2018-2019 permiten evaluar esta hipótesis de las ocupaciones presolutrenses con argumentos estratigráficos, radiocarbónicos y arqueológicos. Se trata de los primeros datos contrastables, cuya discusión incide no sólo sobre la secuencia arqueológica, también sobre la disposición del depósito y su articulación. Al mismo tiempo, reivindica la necesidad de recuperar la información de yacimientos y colecciones.

Esta hipótesis inicial ha abierto también nuevas preguntas sobre la disposición general del yacimien- to, afectado por sucesivos colapsos y desplomes que, intuimos, serán elementos claves para llegar a comprender su proceso de formación, pero también para diseñar cualquier plan de conservación. Las cuestiones abordadas ejemplifican su potencialidad a la hora de obtener nuevos datos y abrir líneas de discusión no planteadas hasta ahora.

\section{EL YACIMIENTO Y SU SECUENCIA}

El yacimiento se encuentra a 122 metros sobre el nivel del mar y a una distancia aproximada de $500 \mathrm{~m}$ de la línea de costa actual del mar Mediterráneo (Fig. 1A y 1B). Según sus primeros exploradores, la cavidad presenta una profundidad de $71 \mathrm{~m}$ (Donat, 1960: 34). Sus coordenadas UTM (ETRS89, huso 30) son 739.630,19 m y 4.341.204,37 m. A partir de finales de la década de los años 50 del siglo XX se generalizó el uso del neotopónimo castellano "Volcán del Faro", ajeno a la tradición local pero que ganó rápidamente predicamento en la literatura. La denominación que se propone en este texto pretende rescatar su topónimo original (Hort de Cortés), asociándolo al consolidado en la literatura arqueológica: Hort de Cortés-Volcán del Faro.

Desde el punto de vista geológico, la cavidad kárstica que contiene el yacimiento arqueológico de HC-VF se encuentra situada en el extremo más suroriental de la Rama Sur de la Cordillera Ibérica (Sopeña y de Vicente, 2004). El aparato kárstico se abre en las brechas poligénicas y calizas. de la Formación Sierra de Utiel de edad Santoniense (Cretácico superior) (IGME en línea) y posiblemente también se desarrolla en las dolomías y calizas recristalizadas del Turoniense (Cretácico superior), que se encuentran al NO de las anteriores limitadas por contacto mecánico, sobre las que descansan de forma concordante las margas amarillentas con intercalaciones de calizas de la Formación Alarcón del Coniaciense (Cretácico superior) que buzan $12^{\circ}$ hacia el SE (IGME en línea). Estas tres formaciones carbonatadas son las responsables del promontorio rocoso que constituye la Muntanya de Cullera o de les Raboses, auténtico islote orográfico (233 m) del Cretáceo superior, que penetra en el mar mediante el Cap Blanc de Cullera, donde se encuentra la cueva. Este promontorio rocoso cretácico está rodeado por los sedimentos cuaternarios de la llanura de inundación del Júcar, que junto con depósitos de turbera se extienden hacia el NO, O y SO del afloramiento, a los que hay que añadir, por el N, depósitos de limos holocenos del extremo S de la Albufera de Valen- 


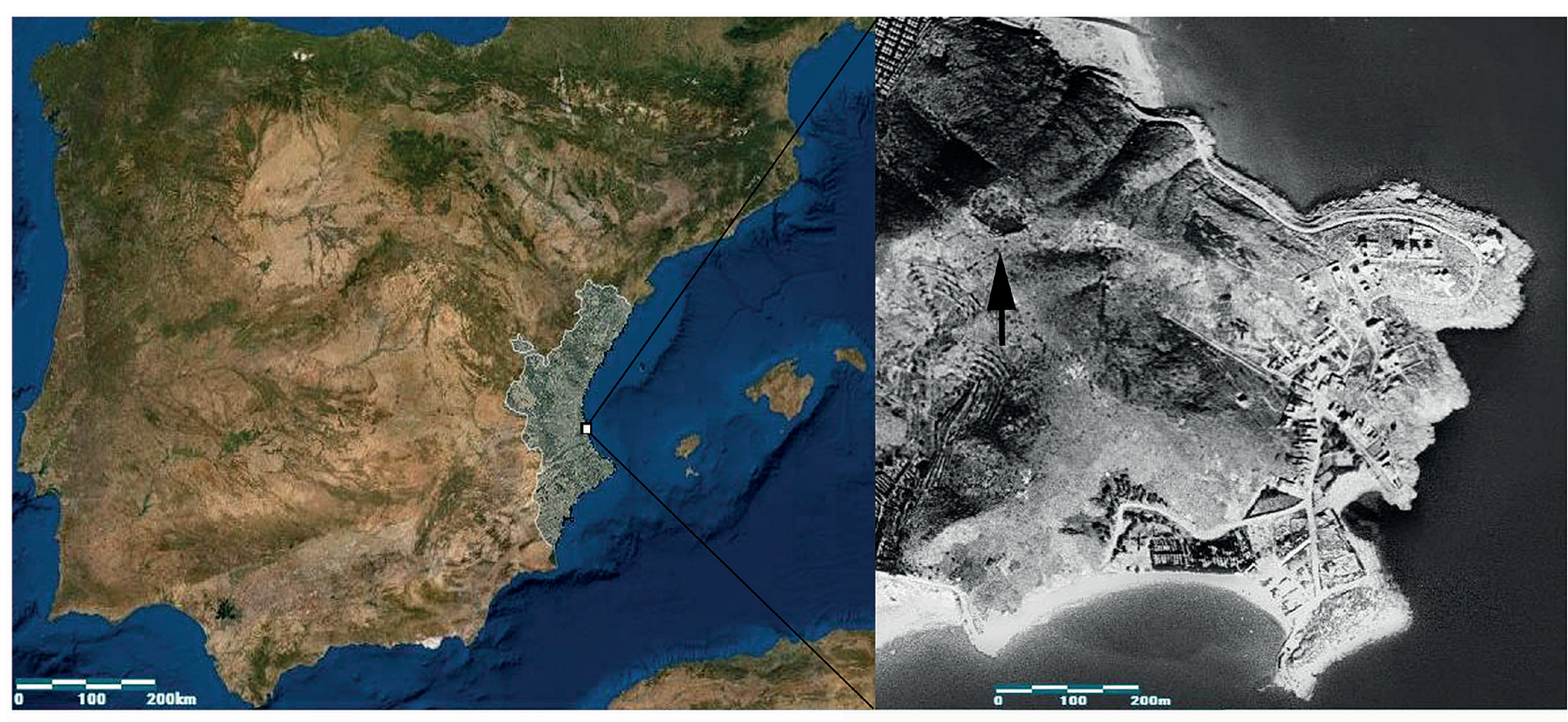

A

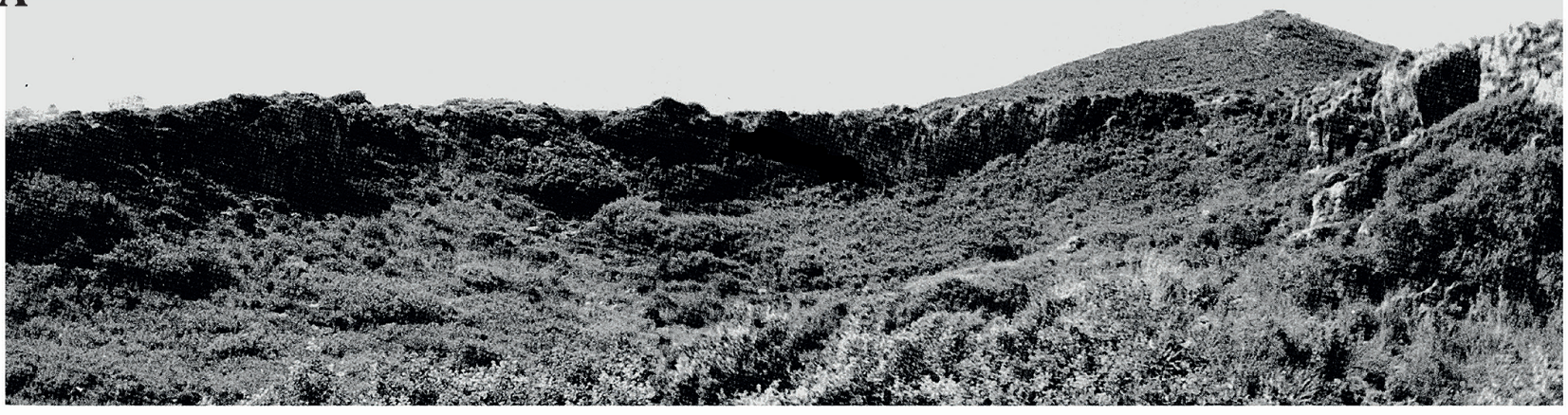

B

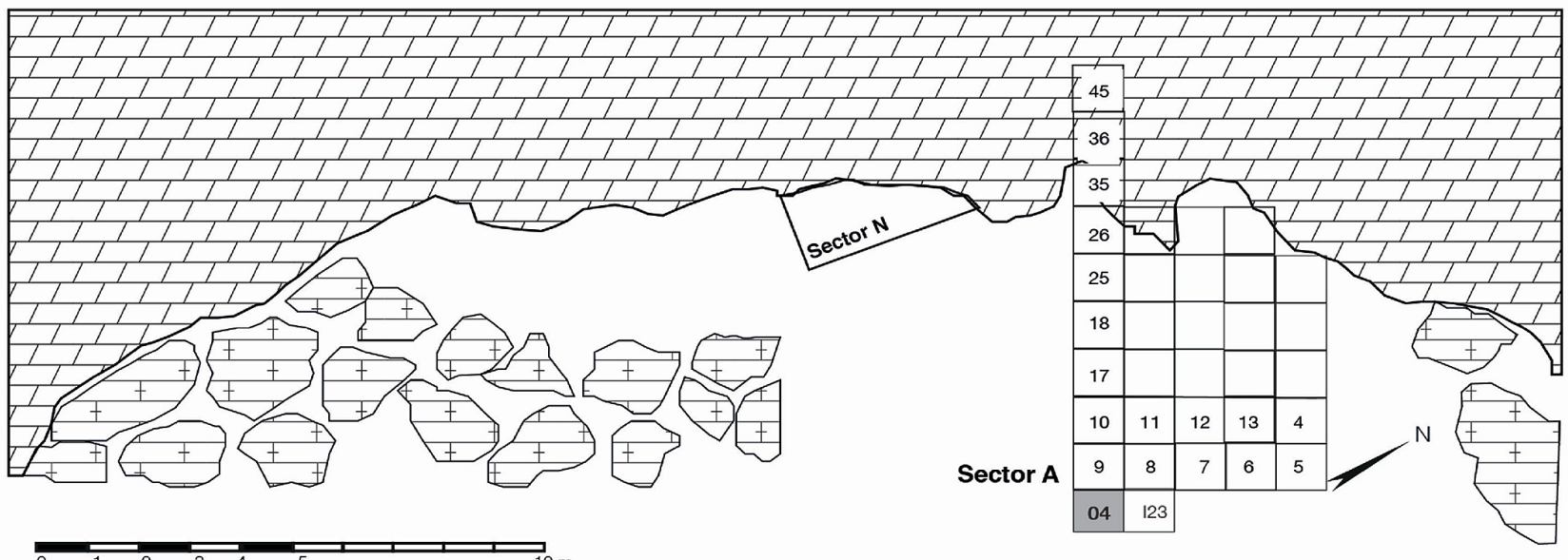

C

Fig.1. Localización de la cova de l'Hort de Cortés - Volcán del Faro (A); fotografía del borde superior de la pared, a partir de Donat ca. 1950 (B); indicación de los sectores y las cuadrículas mencionados en el texto (C). / Location of the cova de l'Hort de Cortés-Volcán del Faro (A); photograph of the upper edge of the wall, after Donat ca. 1950 (B); Indication of the sectors and grids mentioned in the text (C). 
cia. Por su borde N, el promontorio de Cap Blanc está rodeado por un amplio cordón dunar que enlaza con los depósitos de playa que también se extienden al S del Cap Blanc, hasta llegar a la desembocadura del Júcar, donde, tras la línea de playa también se encuentran amplios cordones dunares.

El depósito arqueológico se encuentra estrechamente asociado a una dolina en cubeta colmatada por grandes bloques calizos desprendidos de la visera y por los sedimentos arqueológicos pleistocenos. Entre los bloques se hallan restos de ocupaciones humanas, al menos desde el Paleolítico superior. No cabe descartar que en el mismo yacimiento o en su entorno inmediato se conserven depósitos anteriores, de carácter paleontológico y arqueológico, como es frecuente en el cíngulo meridional de la Albufera (Sarrión Montañana, 1984, 2008).

Entre los años 1968 y 1984 se realizaron XIII campañas de excavación centradas, fundamentalmente, en dos sectores y afectando a una superficie cercana a los $100 \mathrm{~m}^{2}$. Sus resultados fueron avanzados en diversos trabajos hasta la publicación de la memoria en formato de inventario (Aparicio, 2003). Cabe asociar a HC-VF investigaciones pioneras, como el estudio de las estrategias paleoeconómicas y sobre la movilidad durante el Paleolítico superior, con un claro impacto sobre los estudios posteriores (Davidson, 1972, 1976 y 1989). Junto al estudio de la fauna de mamíferos hay que mencionar los dedicados a la malacofauna (Cuerda y Gasull, 1971) y a la avifauna (Eastham, 1973), así como la referencia de los primeros intentos por recuperar frutos y semillas carbonizados.

\subsection{Una secuencia arqueológica con más pre- guntas que respuestas}

Las primeras campañas de excavación permitieron alimentar la idea del descubrimiento de una secuencia paleolítica comparable a la de Parpalló (Fletcher y Aparicio, 1969). Su interés fue destacado por Fortea (1973), proponiendo que los primeros datos conocidos sobre su estratigrafía podrían permitir enlazar el Magdaleniense IV con triángulos escalenos de Parpalló con el Epipaleolítico de les Malladetes. Existe una referencia bastante elocuente sobre la campaña de 1970, en la que se describe “...un Solutreo-gravetiense en principio similar al de Mallaetes o Barranc Blanc (....) y más arriba, escalenos, azagayas, algunas con acanaladuras y un posible protoarpón o arpón dudoso de una hilera de dientes" (Fortea, 1973: 220).

Por su parte, Aparicio proponía que en HC-VF, al igual que en el resto de la región mediterránea, el Magdaleniense había evolucionado hasta la fase IV, convirtiéndose a partir de aquí en un Mesolítico I ", que no es ni más ni menos que la adaptación industrial de la población valenciana, sobre la misma base étnica, a los cambios económicos..." (Aparicio, 1977:10). Una secuencia que rescata propuestas anteriores (Pericot,
1942; Jordá Cerdá, 1949) y en la que no existen referencias a las ocupaciones premagdalenienses.

Las incertidumbre sobre la seriación arqueológica y su cronología también fueron planteadas por Davidson (1989: 189): "Mientras carezcamos de análisis que relacionen los niveles de excavación con la estratigrafía no tendremos más remedio que tomar como secuencia cronológica estos niveles .... (o sea que el nivel 22 del cuadro 5 tendrá la misma cronología que el nivel 22 dela cuadro 35, lo que no está comprobado)"

A la sucesión de materiales del Magdaleniense clásico (escalenos, arpón) y del Solutrense - Solutreogravetiense (puntas de escotadura, pedunculadas, foliáceos bifaciales, puntas de cara plana), se añadió la de un Magdaleniense antiguo de facies badeguliense tipo Parpalló —hoy denominado simplemente Badeguliense (Aura Tortosa, 1988 y 1995: 118).

También Casabó (2004) ensayó una correlación entre los dos sectores principales de excavación. Su propuesta evidenciaba las contradicciones de que adolecía la excavación y abogaba por una posición estratigráfica discordante entre industria lítica y ósea.

Por último, Soler et al. (2013) propusieron una "reconstrucción hipotética" de la estratigrafía, a partir de los datos de la memoria (Aparicio, 2003). Las conclusiones planteaban una relectura de la secuencia arqueológica del sector $A$ :

- En la base se reconocen suficientes elementos diagnósticos como para plantear la existencia de materiales gravetienses sobre los que se superponen las capas con puntas de cara plana, escotadas,y piezas bifaciales de retoque plano. Por su parte, en el sector N, los materiales asociados al bastón perforado, indicaban ocupaciones del Solutrense evolucionado / Solutreogravetiense. A pesar de esta constatación, existe una repetida consideración de los morfotipos solutrenses como magdalenienses, llegando a referirse a la punta de pedúnculo y aletas de la Capa 29 del Sector A como "una sensacional punta pedunculada, sumamente acuminada, con retoques planos bifaciales cubriendo toda la superficie, de técnica totalmente Solutrense pero de época Magdaleniense" (Aparicio, 2003: 323).

- Las capas con microraederas, raclettes y azagayas de sección circular y aplanada permiten reconocer ocupaciones del Badeguliense, en las que se identifican todavía alguna punta escotada.

- Las capas con raspadores, buriles y hojitas de dorso los decantaban hacia un Magdaleniense clásico, con presencia de triángulos escalenos y un posible arpón de dientes unilaterales, similar a los de Parpalló.

- Por último, en las capas superiores se describe una industria lítica genérica, formada por raspadores, buriles y hojitas de dorso. En las capas superficiales se produce un aumento exponencial de la fauna malacológica marina asociada a fragmentos cerámicos. 


\section{MATERIALES Y MÉTODOS}

Los nuevos datos estratigráficos, micromorfológicos, industriales y radiocarbónicos obtenidos en los trabajos realizados en la cuadrícula $\mathrm{O} 4$, situada en el límite externo del Sector $A$, serán las bases utilizadas en este trabajo (Fig. 1C). Junto a la descripción estratigráfica, se han realizado varias analíticas para caracterizar y datar la formación del depósito.

\subsection{Las costras laminadas}

En la campaña de 2018 se obtuvo del corte frontal posterior de $\mathrm{O} 4$ un fragmento de la costra descrita como Unidad III para explorar sus posibilidades de datación (Fig. 2). Esta cuadrícula se sitúa alejada de la protección de la actual pared-bóveda de la cavidad y su identificación planteaba la posibilidad de un proceso de sellado del depósito y, por tanto, ciertas garantías de integridad a muro de su desarrollo. Además, podía aportar una referencia cronológica para un depósito que no había aportado materiales susceptibles de datación. La muestra fue enviada al CENIEH para su valoración y procesado.

Los dos retos mayores a los que se enfrenta el método de datación por series de uranio son, por un lado, la medida con precisión de las relaciones isotópicas en muestras pequeñas (poca disponibilidad o por extracción con ablación láser) con contenido muy bajo de uranio y torio, y por otro lado, la interpretación de los resultados provenientes de análisis de materiales que se consideran sistemas abiertos y de materiales biológicos.

En el caso de los sistemas abiertos, el uranio y torio pueden entrar y salir del espécimen de ensayo durante cualquier momento después de su formación o depó- sito. Así, la introducción de uranio provocará que los resultados de las medidas conduzcan a edades más jóvenes mientras que la pérdida de uranio simulará un envejecimiento de la muestra. Igualmente, la incorporación de torio externo, siempre lleva asociada un aporte de 230Th, que provocaría una distorsión de los resultados hacia dataciones más antiguas, ya que el 230Th inicial no será cero, como sería deseable. Las arcillas y materiales de grano fino tienen una gran capacidad de adsorción de torio, incrementándose esta cuanta más pequeña es la partícula (arcillas, limo), por lo que la presencia de estas sustancias en la muestra supone generalmente un aporte adicional de 230Th al soportado por el decaimiento del $238 \mathrm{U}$, perturbando de manera importante la interpretación de los resultados de las dataciones. En ambos casos existen estrategias para la obtención y corrección de las fechas obtenidas, dentro de unos ciertos límites. Estas correcciones Ilevan asociadas, a su vez, fuentes de incertidumbre en la medida, lo que podría conducir a la situación de obtener resultados de interpretación imposible.

\subsection{Lámina delgada}

Paralelamente, se obtuvo una muestra inalterada de la capa 3 (Unidad II) sobre el perfil sagital sur de la cuadrícula $\mathrm{O} 4$, consolidando el perímetro de un bloque $(10 \times 8 \times 5 \mathrm{~cm})$ con bandas de escayola para que la muestra no se disgregara ni en el proceso de extracción ni durante el transporte posterior al laboratorio.

El bloque fue enviado al Laboratorio de Micromorfología y Análisis de Imágenes de la Universidad de Lleida, donde se confeccionó la lámina delgada siguiendo el protocolo desarrollado por el Département des Sols de l'Institut National Agronomique de Plaisir-Grignon (France) por P. Guilloré (1980) y por el Departament de
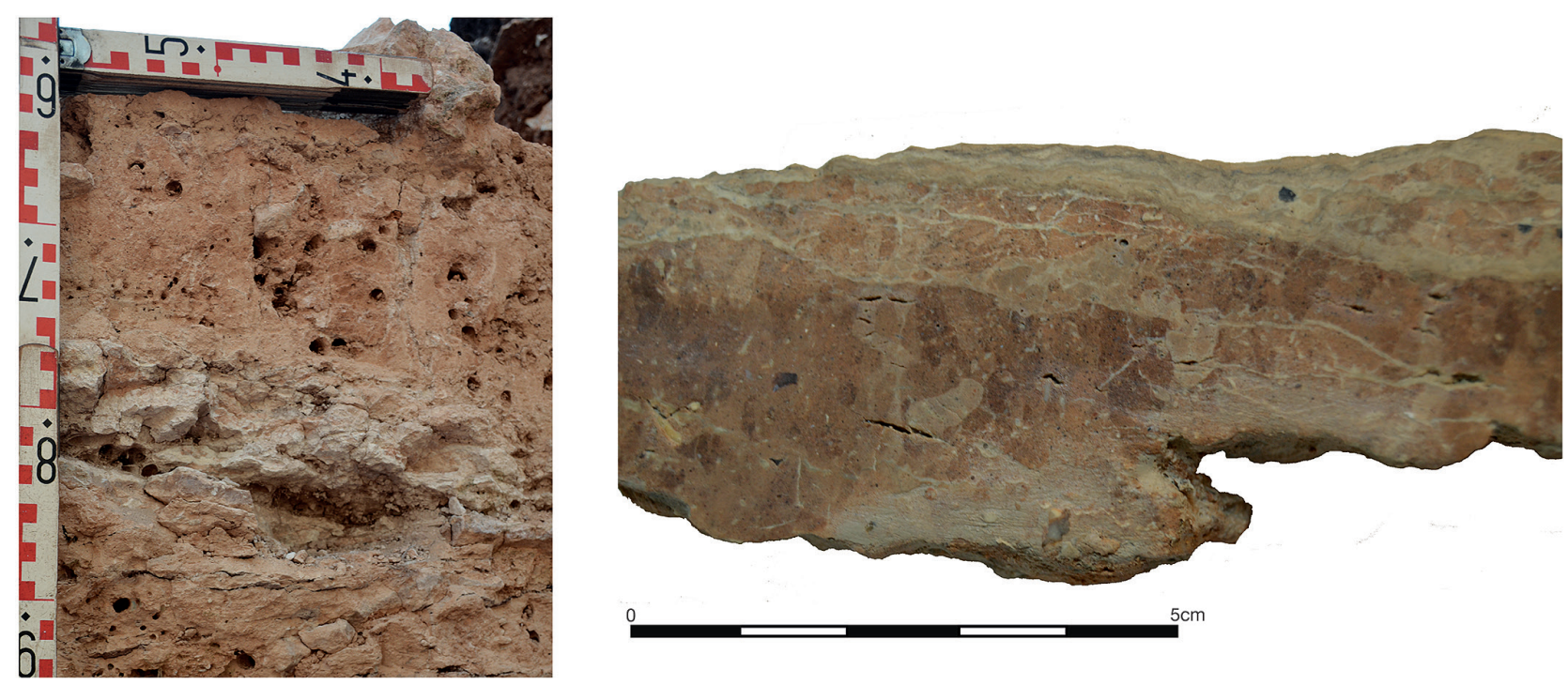

Fig.2. HC.VF. Vista en corte de la costra laminada y muestra en fase de preparación. / HC · VF. Sectional view of the laminated crust and sample under preparation. 
Medi Ambient i Ciències del Sòl de la Universitat de Lleida. Para la realización de la lámina delgada fue necesario la utilización de una cámara de vacío en donde se introdujo el bloque muestreado, incorporando de manera progresiva resinas sintéticas diluidas que impregnaron la muestra hasta el interior de los poros intersticiales. Una vez se produjo el endurecimiento de las resinas, se pasó al proceso de corte y pulido que permitió obtener secciones longitudinales sobre lámina de vidrio de gran formato $(13 \times 5 \mathrm{~cm})$, con un espesor inferior a $25 \mu \mathrm{m}$ tras el pulido. Para la observación y estudio de esta lámina se ha utilizado el microscopio óptico petrográfico polarizante marca Olympus BX-41, Sistema óptico UIS, y se han seguido los principios de descripción utilizados por Bullock et al. (1985) y Fitz Patrick (1993).

\subsection{Datación radiocarbónica}

La campaña de 2019 ha permitido recuperar unos pocos restos de carbón que han podido ser identificados a nivel taxonómico y posteriormente datados mediante AMS por Beta Analytic. Se trata de la primera datación obtenida en el actual proyecto de documentación de los cortes estratigráficos.

\subsection{Industrias líticas talladas}

Por último, se han analizado las industrias líticas de la cuadrícula $\mathrm{O} 4$ de las campañas de 2018 y 2019. Las capas de la Unidad superficial, denominadas como, "Húmico superficial negro" y "Húmico superficial marrón", han sido agrupadas, debido a que comparten características del sedimento y cierta heterogeneidad de los elementos que contienen, debido a su carácter superficial. Para el análisis del conjunto lítico sólo se tendrán en cuenta las capas 1 a 8.

El total de piezas estudiadas asciende a 1816. El material presenta un alto grado de deshidratación. Además, el sedimento está fuertemente compactado por carbonatación, lo que ha contribuido a la fracturación de las piezas durante su recuperación. Por lo que se refiere a la economía de las materias primas, no se han realizado todavía estudios en detalle debido al estado del material. No obstante, el sílex es la materia prima mayoritaria y se ha caracterizado de forma macroscópica atendiendo a diferentes variables como la transparencia, el color, la estructura, la presencia de inclusiones y el tipo de córtex.

El estudio de estos materiales se ha realizado a partir de una aproximación tecnológica (Perlès, 1991; Inizan et al., 1995; Pelegrin, 2000) y tipológica (Sonneville-Bordes y Perrot, 1954, 1955, 1956a y 1956b). Debido a las características del material, nos hemos centrado en la identificación de las categorías tecnológicas que definen las fases de la cadena operativa. Por último, se han planteado apreciaciones en relación a los objetivos de la talla, aunque no se ha podido ir más allá en la interpretación de los sistemas de producción.

\section{RESULTADOS}

\subsection{Estratigrafía del corte frontal posterior este (TFE)}

Los únicos cortes del sector A correspondientes a las excavaciones realizadas entre 1969 y 1984 que han podido ser reconocidos son el sagital sur (=TSS) (Aparicio, 2003: fig. 105) y el frontal este (=TFE). Hasta ahora, la limpieza y documentación de este último ha permitido obtener una información limitada pero relevante.

Este corte TFE y la excavación de la cuadrícula O4 permitieron reconocer unos depósitos muy carbonatados entre los que se suceden costras y grandes bloques relacionables con importantes colapsos. La descripción que incluimos es la realizada durante el trabajo de campo, sin mediar ninguna analítica, corresponde a un tramo de $80 \mathrm{~cm}$ excavado hasta ahora (Fig. 3).

\section{TFE 04. Unidad S (húmico-negro-marrón) (10-18cm)}

Se trata de los sedimentos más superficiales de coloración negra por la presencia de materia orgánica, tono que se torna marrón a medida que se profundiza. Incluye materiales variados: cerámica a mano y a torno, malacofauna marina y restos líticos tallados paleolíticos, si nos atenemos a su tecno-tipología.

TFE O4. Unidad I (15 - 18cm)

Arenas y gravas de coloración marrón, que en planta muestran un tono más grisáceo y bloques de tamaño medio. Puntualmente, muestra superficies de carbonatación. Esta Unidad fue excavada como capas 1 y 2.

\section{TFE. O4. Unidad I/ (10-32cm)}

Arenas de coloración rosácea carbonatadas y cementadas, muestran un contacto discordante a techo. Corresponde a las capas 3, 4, 5 y 6.

\section{TFE 04. Unidad III (10-18cm)}

En el frontal posterior se corresponde a dos laminaciones de costras sub-horizontales, que llegan a entrecruzarse, con buzamiento hacia NE-E. Presenta arcillas, quizás también materia orgánica actual (¿raíces?) intercaladas que alteran su tramo medio. En el frontal anterior, esta laminación separa las Unidades II y III. Hasta ahora se han excavado dos capas, la 7 y 8.

\section{TFE O4. Unidad IV $(40-50 \mathrm{~cm})$}

En la que se reconocen 3 tramos:

a) a techo, arenas de coloración rosácea con bloques de tamaño medio, desordenados,

b) tramo medio, con arenas y plaquetas sub-horizontales,

c) a muro, con más arcillas, acumula fracción de calibre desigual y disposición irregular.

Hasta ahora sólo se han excavado las unidades I a III y sus materiales serán los analizados en este trabajo. 


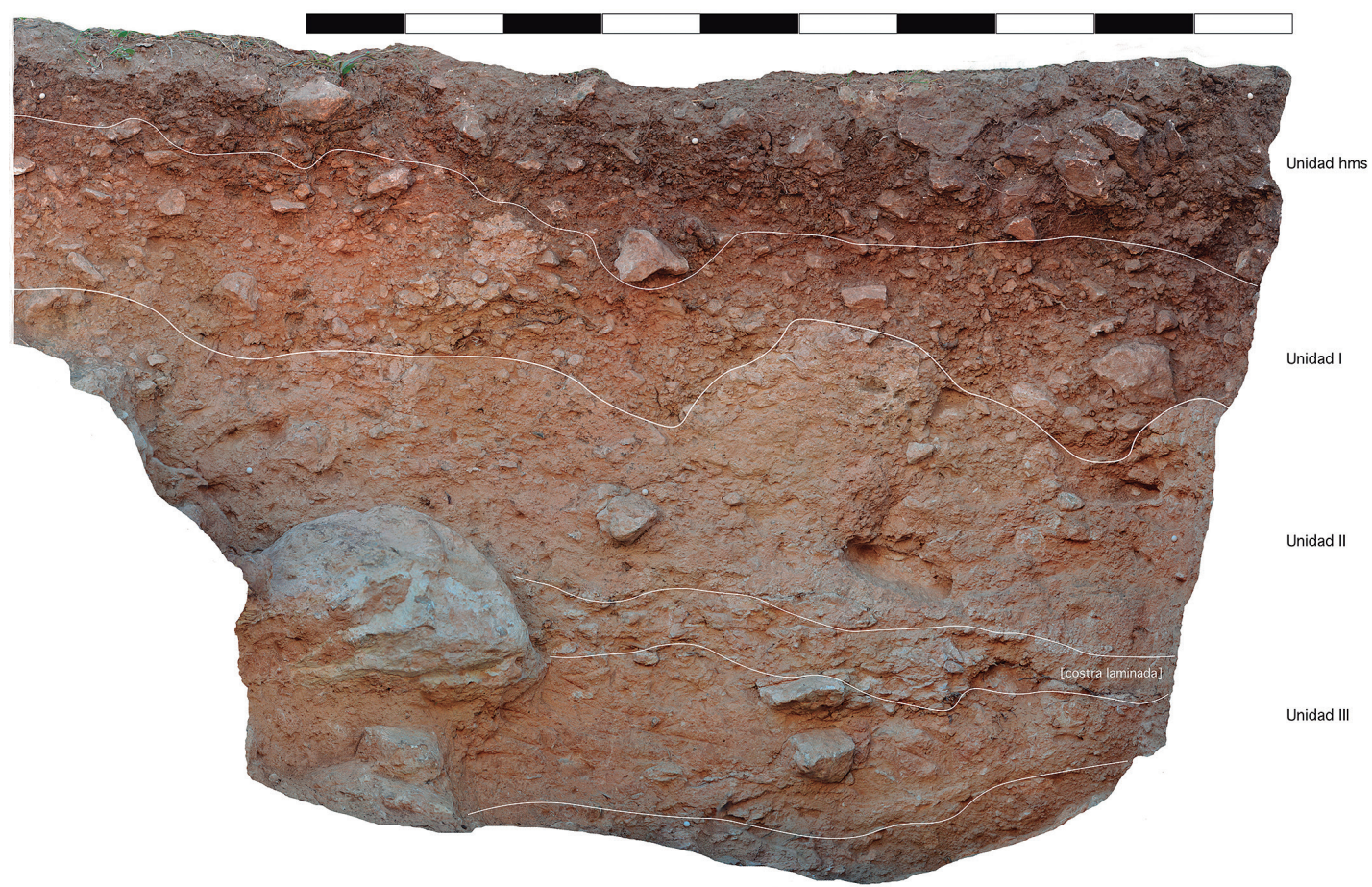

Fig.3. HC.VF. Corte frontal anterior de $\mathrm{O} 4$ y parte de $\mathrm{O} 3$ con indicación de las unidades reconocidas. / $\mathrm{HC} \cdot$ VF. Frontal section of $\mathrm{O} 4$ and part of $\mathrm{O} 3$ with indication of the recognized lithostratigraphic units.

\subsection{Lámina delgada}

El análisis de la lámina VF-HC/18, capa 3 (Unidad II), nos muestra un depósito con alta porosidad y micromasa calcítica de color rojo-pardo. Existen hasta 3 laminaciones, entre 3,00-1,00 cm de potencia, de un marcado carácter masivo en posición subtabular. Igualmente, se observan cortes erosivos claros, de entre 100-500 $\mu \mathrm{m}$, entre laminaciones, compuestas por diversos tipos de fracción. Se han reconocido las siguientes formaciones morfoestructurales:

- Clastos calcáreos de contornos subangulares a subredondeados, de tamaño heterométrico, siendo los más frecuentes los de diámetro $>1 \mathrm{~cm}$, depositados de manera caótica, sin una clara disposición ni dirección dominante. Aparece también de manera generalizada y sin orientación clara, fragmentos de exoesqueletos calcáreos de moluscos (Fig. 4: 1 y 9).

- Agregados de carácter subredondeados a redondeados de tamaño heterométrico, abundando el diámetro $<1 \mathrm{~mm}$, con una matriz de arcillas micríticas y clastos calcáreos de pequeño tamaño, de color rojo intenso que parece recordar a arcillas de descalcificación (Fig. 4: 5 y 8).

- La matriz micrítica del depósito ha desaparecido de forma general, erosionada por procesos genéticos y edafogénicos que le dan una marcada textura de empobrecimiento.

El proceso formativo parece corresponder a flujos plásticos de tipo mud flow, con gran carga de partículas, depositándose las más groseras de manera caótica, en cambio las más finas están ausentes por haber sido lavadas (Fig. 4: 3 y 4).
Los procesos postdeposicionales abundan y se distribuyen de manera generalizada por toda la lámina. Los más significativos son los procesos hidromórficos de infiltración y calcificación, con precipitados aciculares en canales y fisuras, así como la actividad biológica (Fig. 4:2 y 6).

\subsection{Datación radiocarbónica}

En las 8 capas practicadas en la cuadrícula $\mathrm{O} 4$ apenas se recogieron restos orgánicos carbonizados, pues los restos bioarqueológicos tienen una mala conservación en las cuadrículas alejadas de la protección de la antigua visera. En el caso de los restos de fauna están fuertemente carbonatados, al igual que ocurre con la industria lítica.

Uno de los escasos restos de carbón que por su tamaño y peso era susceptible de poder ser datado procede de la capa 8 (ID: 551) y por sus características fue identificado como Pinus nigra-sylvestris. Una especie común durante el Pleniglacial y Tardiglacial en nuestra región (Badal y Carrión, 2001)

El resultado obtenido en la datación AMS ha sido $23640 \pm 110$ BP (Beta - 542718), que una vez calibrada aporta un intervalo de edad entre 27939 y 27547 años cal BP, con un 95,4\% de probabilidad (Fig. 5). La calibración ha sido realizada utilizando OxCal v4. 3 (Bronk Ramsey, 2017), con la curva IntCal 13 (Reimer et al., 2013). El resultado es compatible con varios conjuntos atribuidos al Gravetiense descritos en yacimientos localizados en las comarcas centrales valencianas: Malladetes y Cendres (Villaverde et al., 2019), Comte (Casabó et al., 2017) y Casa dels Moliners (Miret et al., 2016). 


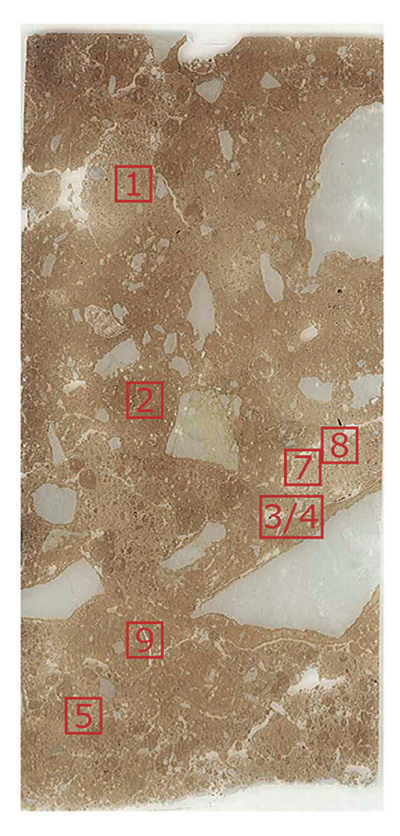

$1: 100$
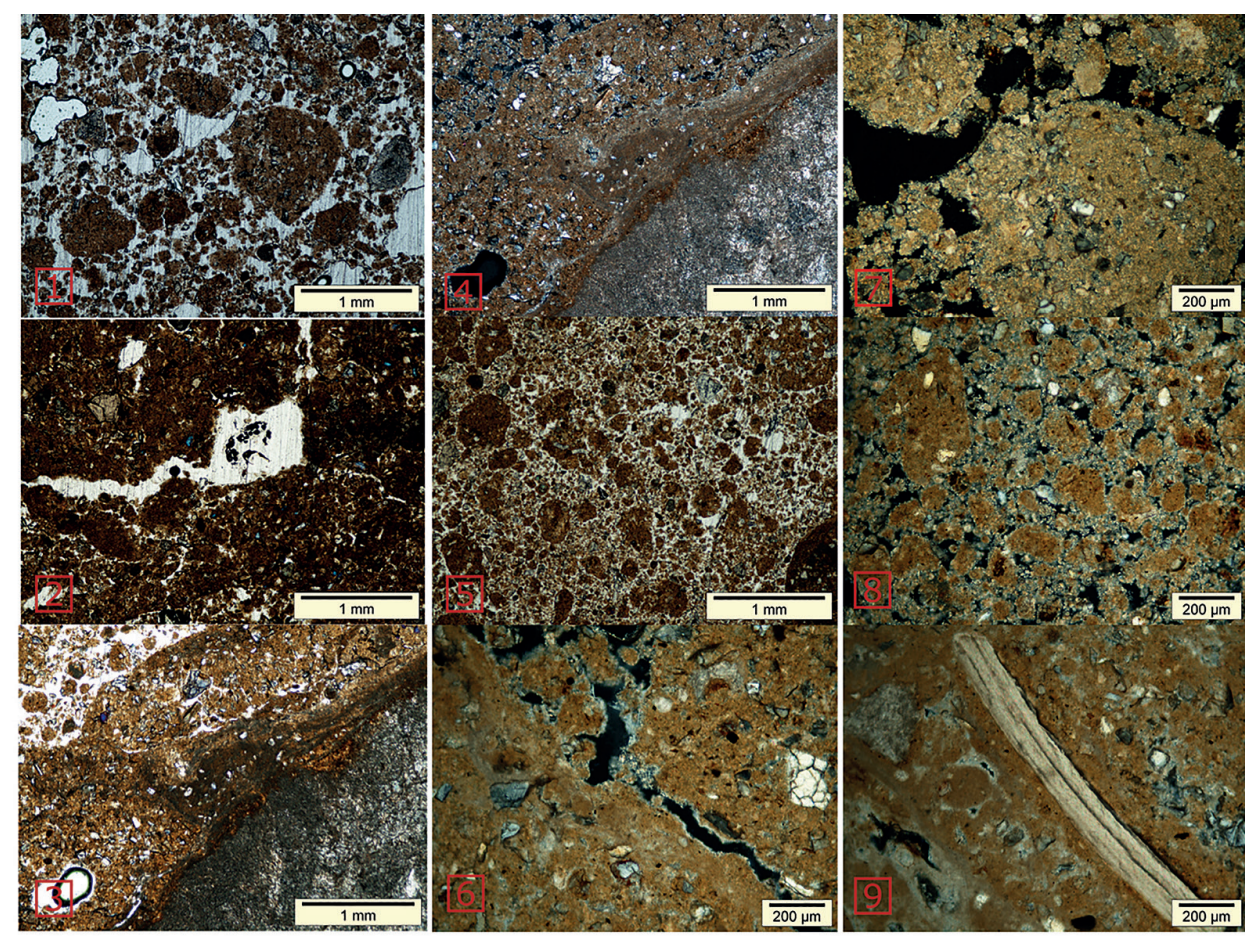

Fig.4. HC.VF, cuadrícula O4. Lámina delgada: 1 Conglomerados redondeados en posición caótica con fracción fina inexistente 10x PLX.; 2 Cavidades endolíticas. 4X PPL; 3 Revestimiento laminar calcáreo 10x PPL: 4 Revestimiento laminar calcáreo $4 x$ PLX; 5 Agregados redondeados y matríz empobrecida. $4 \times$ PPL; 6 Revestimiento acicular de cavidades endolíticas 4X PLX; 7 Edaforrastros de empobrecimiento y agregados subredondeados. 4x PPL.; 8 Basal micrítico y edaforrastros de empobrecimiento. 10x PLX; 9 Fragmento exoesqueleto molusco. 10X PLX. / HC · VF, grid O4. micrographs: 1 Rounded conglomerates in chaotic position with nonexistent fine fraction 10X PLX .; 2 Endolytic cavities. 4X PPL; 3 Calcareous lamellar coating 10x PPL .; 4 4X PLX calcareous lamellar coating; 5 Rounded aggregates and impoverished matrix. 4x PPL; 6 Acicular lining of endolytic cavities 4X PLX; 7 Impoverishment edaphotraces and under-rounded aggregates. 4x PPL .; 8 Micritic basal and impoverishment edaphotraces. 10x PLX; 9 Exoskeleton mollusk fragment. 10X PLX.
Fig.5. Calibración de las fechas del Gravetiense regional. Se destaca la obtenida en HC.VF, O4, capa 8. / Calibrated dates for the regional Gravettian. The AMS date from $\mathrm{HC}$ $\mathrm{VF}, \mathrm{O} 4$, layer 8 is highlighted. 


\subsection{Industrias líticas}

El conjunto analizado (Tabla 1) está compuesto mayoritariamente por elementos de sílex (94,6\%; $n=547)$, aunque en gran parte de ellos no hemos podido determinar el tipo de materia prima $(76,8 \% ; n=438)$ debido sobre todo al estado de deshidratación y desilificacion (S102) aunque también han intervenido en ello la alteración térmica de las piezas (S101) y el alto grado de concreción (S103). Algunas de las piezas de sílex nos han permitido realizar una descripción macroscópica, a partir de lo cual hemos establecido la presencia de 6 tipos diferentes (Tabla 2). Aunque no se ha realizado todavía un estudio sobre la procedencia de las materias primas, sí que podemos realizar ciertas apreciaciones a través de la observación del córtex. Mayoritariamente aparece rodado, lo que indica que los volúmenes seleccionados corresponden a cantos. En algunas piezas el rodamiento del córtex y la morfología general plantea su posible procedencia marina, mientras que en otros casos la captación sería aluvial. Así pues, podemos indicar diferentes entornos de captación, sin poder traspasar por ahora esta descripción.

A pesar de que el sílex es la materia más representada, se ha reconocido la presencia de caliza y de

\begin{tabular}{|c|c|c|}
\hline Materia Prima & Totales & $\%$ \\
\hline SÍLEX VF1 & 2 & $0,30 \%$ \\
\hline SÍLEX VF2 & 11 & $1,90 \%$ \\
\hline SÍLEX VF3 & 28 & $4,80 \%$ \\
\hline SíLEX VF4 & 37 & $6,40 \%$ \\
\hline SíLEX VF5 & 3 & $0,50 \%$ \\
\hline SÍLEX VF6 & 22 & $3,80 \%$ \\
\hline CALIZA & 28 & $4,80 \%$ \\
\hline CALIZA/SÍLEX & 2 & $0,30 \%$ \\
\hline CUARCITA & 1 & $0,20 \%$ \\
\hline SI01 & 5 & $0,90 \%$ \\
\hline SI02 & 438 & $75,80 \%$ \\
\hline SI03 & 1 & $0,20 \%$ \\
\hline TOTAL & 578 & 100 \\
\hline
\end{tabular}

Tabla 1: HC.VF, cuadrícula O4. Número total y porcentual de piezas asociadas a las diferentes materias primas identificadas. / HC · VF, grid $\mathrm{O} 4$ Total and percentage number of pieces associated with the different raw materials identified. cuarcita. En el primer caso, se trata de 28 elementos, representando así un 4,8\% del total de piezas analizadas. En 2 piezas más hemos tenido dudas en su clasificación bien como caliza o bien como sílex, debido a su estado. En cuanto a la cuarcita solo hemos recuperado un núcleo de notables dimensiones $(69,11 \times 50,00$ x 30,92), que presenta un córtex rodado que por sus características puede tener una procedencia marina.

El numero de piezas es reducido. En la Tabla 3 aparecen las diferentes categorías tecnológicas identificadas y la asociación con las capas correspondientes.

Los núcleos son escasos en todas las capas, incluso en algunas, como en las capas 4 y 5 , no hemos recuperado ninguno. Contamos pues con un total de 14 elementos. La mayoría de ellos son de sílex $(n=12)$, identificándose asimismo un volumen de caliza y otro de cuarcita. En la mayoría de los volúmenes de sílex $(n=8)$ no se ha podido identificar la materia prima debido a su deshidratación. En los volúmenes en que hemos podido identificar los tipos, estos se corresponden con los definidos como VF1, VF2, VF3 y VF5. La extensión de las concreciones calcáreas y la fracturación han impedido realizar un análisis exhaustivo en 6 de los volúmenes clasificados como núcleos. Otros 2 han sido identificados como núcleos testados, lo cual indica un transporte íntegro de la materia al yacimiento. De los 6 núcleos restantes la mayor parte de ellos estarían destinados a la obtención de productos laminares de dimensiones variadas, ya que encontramos negativos en las superficies explotadas que van desde los 5 hasta los $16 \mathrm{~mm}$ de ancho. Las dimensiones más altas corresponden a los núcleos presentes en la capa 8; solo en la capa 2 se ha recuperado un núcleo relacionado con la obtención de lascas.

Se observa cierta diversidad en cuanto a la delineación que sigue la superficie de talla, en algunos casos restringida a la cara estrecha, en otros casos sobre la cara ancha, reconociéndose tanto explotaciones semienvolventes como sobre flanco. Por lo que se refiere a la dinámica de explotación se trata de explotaciones unidireccionales, salvo en uno de los núcleos.

En relación a los productos de la talla, las lascas son más numerosas en las capas analizadas. No obstante, esta diferencia se atenúa a partir de la capa 5, podemos pensar en que los objetivos de la talla se centran sobre todo en la obtención de productos laminares.

\begin{tabular}{|c|c|c|c|c|c|}
\hline MP & Transparencia & Color & Estructura & Inclusiones & Tipo de córtex \\
\hline VF1 & de opaco a translúcido & marrón caramelo & homogénea grano fino & - & indeterminable \\
\hline VF2 & opaco & blanquecino & homogénea grado medio & foraminíferos & indeterminable \\
\hline VF3 & opaco & beige lechoso & homogénea grano fino & blancas & fluvial \\
\hline VF4 & opaco & marrón claro & heterogénea grano fino & puntos rojos o negros & fluvial \\
\hline VF5 & opaco & gris & heterogénea grano fino & vetas sinuosas blancas y grises & marino \\
\hline VF6 & opaco & gris & homogénea grano fino & vetas rojas & fluvial \\
\hline
\end{tabular}

Tabla 2: HC.VF, cuadrícula O4. Caracterización macroscópica de los tipos de sílex identificados. / HC · VF, grid O4. Macroscopic characterization of the identified flint types. 


\begin{tabular}{|c|c|c|c|c|c|c|c|c|c|}
\hline Cuadro & Capas & Núcleos & $\begin{array}{l}\text { P. de acondicio- } \\
\text { namiento }\end{array}$ & Lascas & $\begin{array}{l}\text { Productos } \\
\text { laminares }\end{array}$ & Frag. indet & Débris & Retocados & TOTAL \\
\hline \multirow{12}{*}{04} & Superficial & 9 & 11 & 49 & 39 & 27 & 34 & 17 & 187 \\
\hline & Húmico superf negro & 4 & 7 & 30 & 45 & 60 & 110 & 13 & 269 \\
\hline & Húmico superf marrón & 9 & 7 & 58 & 21 & 38 & 95 & 9 & 237 \\
\hline & 1 & 1 & 4 & 45 & 12 & 29 & 42 & 5 & 138 \\
\hline & 2 & 3 & 4 & 133 & 41 & 80 & 87 & 6 & 354 \\
\hline & 3 & 2 & 1 & 73 & 25 & 61 & 40 & 2 & 204 \\
\hline & 4 & 0 & 1 & 27 & 7 & 21 & 13 & 0 & 69 \\
\hline & 5 & 0 & 0 & 16 & 2 & 10 & 5 & 0 & 33 \\
\hline & 6 & 1 & 2 & 30 & 14 & 43 & 15 & 0 & 105 \\
\hline & 7 & 1 & 1 & 34 & 14 & 23 & 18 & 3 & 94 \\
\hline & 8 & 6 & 2 & 39 & 20 & 42 & 16 & 1 & 126 \\
\hline & TOTALES & 36 & 40 & 534 & 240 & 434 & 475 & 56 & 1816 \\
\hline
\end{tabular}

Tabla 3: HC.VF, cuadrícula O4. Materiales organizados por capas y por categorías tecnológicas. / HC · VF, grid O4. Materials organized by layers and technological categories.
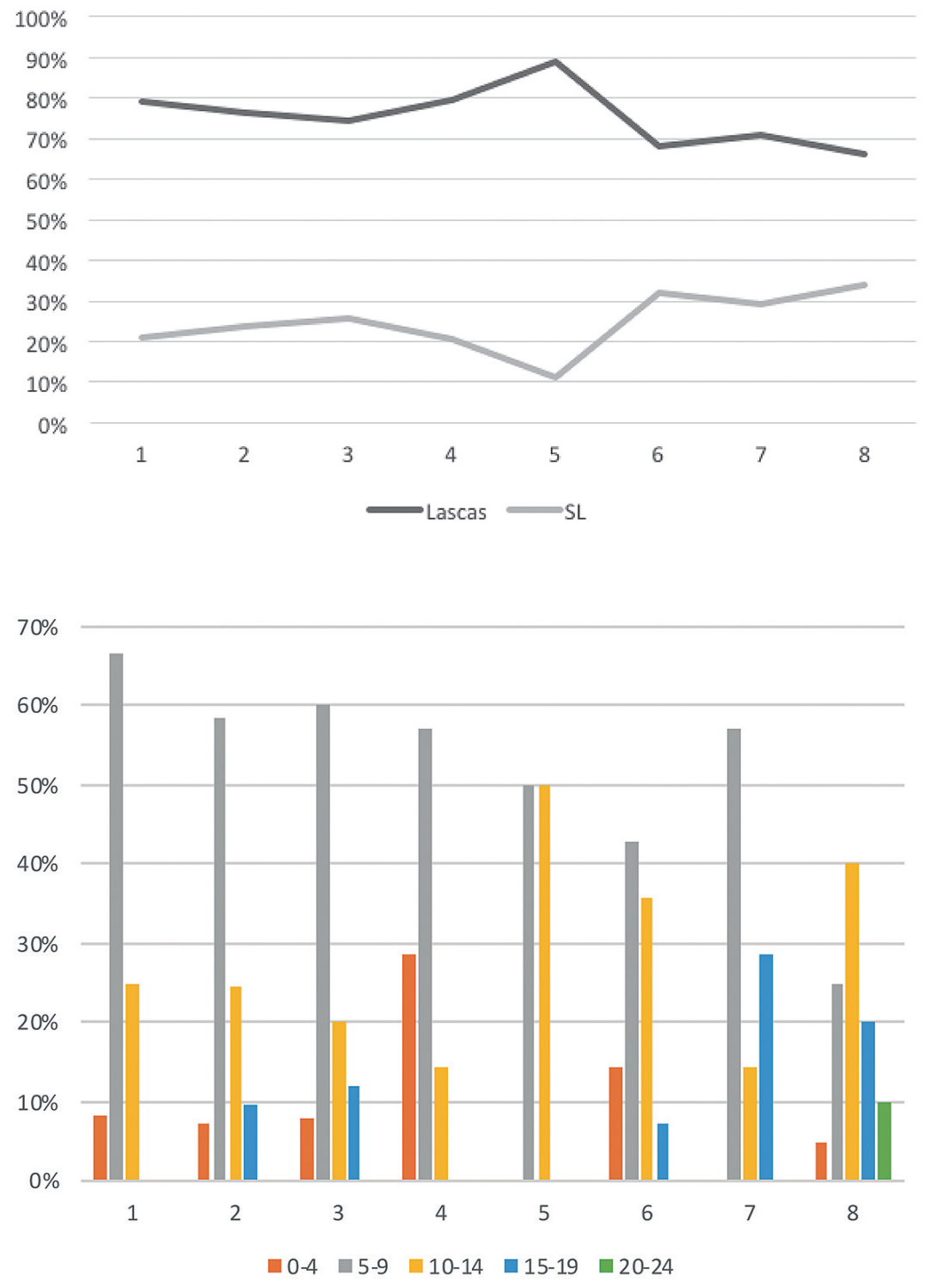

Fig.6. HC.VF, industria lítica de la cuadrícula O4. Porcentajes de lascas y láminas por capas. / HC · VF, lithic industry of grid $\mathrm{O} 4$. Percentages of flakes and blades by layers.

Fig.7. HC.VF, industria lítica de la cuadrícula O4. Anchura de los productos laminares de plena talla. / HC $\mathrm{VF}$, lithic industry of grid $\mathrm{O} 4$. Changes on blades width. 
En relación a estos productos de talla, la Figura 7 muestra las dimensiones en relación a la anchura de los productos laminares de plena talla. Su observación permite apreciar un predominio de los productos de una anchura comprendida entre los 5 y los $9 \mathrm{~mm}$ en las capas 1 a la 7 , mientras que en la capa 8 se observa un predominio en el grupo que comprende los valores entre 10 y $14 \mathrm{~mm}$. El predominio del grupo entre $5-9 \mathrm{~mm}$, no obstante, va decreciendo, en favor de los módulos con unas dimensiones mayores. En las capas 7 y 8 se documentan productos de entre 15 y $19 \mathrm{~mm}$, que en las capas anteriores o no estaban presentes, o lo estaban generalmente en porcentajes por debajo del 10\%, en estas 2 capas se sitúan entre un 20 y un $30 \%$. Asimismo, en la capa 8 aparecen por primera vez productos laminares con una anchura comprendida entre los 20 y los $24 \mathrm{~mm}$. Estos elementos muestran una tendencia a la búsqueda de una producción laminar de una mayor anchura.

Los elementos retocados recuperados son escasos, pero lo son aún más en las capas 1-8, con lo que las apreciaciones que podemos hacer en este sentido son limitadas y provisionales (Tabla 4).

La presencia de algunos tipos resulta destacable. Se trata de la identificación de raclettes, (Fig. 8:12) en los niveles superficiales y en la capa 2, un tipo asociado al Badeguliense reconocido por algunos autores (Aura Tortosa, 1995). Por otra parte, la presencia de la base de una hoja de laurel bifacial remite al Solutrense (Fig.8:12). Por último, los raspadores que encontramos en las capas 7 y 8 están obtenidos sobre productos laminares de dimensiones considerables, entre los $15-19 \mathrm{~mm}$ de anchura (Fig.9:1-2). Si bien no se pueden asociar a una cronología concreta, sí que podemos señalar que son escasos en las fases microlaminares del Paleolítico superior final. Destaca la ausencia de buriles en las 8 capas, en contraste con el material más superficial y algo similar ocurre con las armaduras concentradas sobre todo en la unidad superficial y en la 1 (Fig. 8:1-4). Dentro de este último grupo encontramos que la mayor parte son fragmentos de productos laminares con un dorso retocado de manera abrupta, o laminitas con el dorso abatido. Solamente aparece un elemento apuntado en la capa 3, se trata de una bipunta con un dorso rectilíneo (Fig. 8:10).

\section{DISCUSIÓN}

Las dos campañas de excavación efectuadas en 2018 y 2019 han contribuido a despejar ciertas incertidumbres, pero también han abierto nuevos interrogantes. La cuadrícula $\mathrm{O} 4$ se encuentra en el límite externo del sector A y, en buena lógica, la información obtenida podría ser contrastada con la obtenida en sus cuadros adyacentes de este Sector.

La Unidad superficial ( $\mathrm{nmh}$ ) tiene una formación reciente y engloba materiales históricos —cerámica, fibrocemento y metal- pero también industrias líticas talladas de tipología paleolítica. A este tramo de materiales sueltos y heterogéneos le suceden unidades cada vez más compactas, cementadas, hasta reconocer las costras que forman la Unidad III. Desde el techo de la unidad II se identifican procesos hidromórficos de infiltración y calcificación, con sucesivas laminaciones subtabulares, depositadas durante procesos de solifluxión con desplazamiento masivos y lentos por gravedad, en un ambiente húmedo que ha propiciado el lavado de la matriz más fina y, por tanto, su desaparición (Figura 4:1, 7 y 8). Además, aparece una laminación relicta intercalada compuesta por arcillas estratificadas que reforzaría la idea de este proceso de mud flow con lavado de las partículas más finas (Figura 4: 3 y 4). Estos depósitos han sufrido procesos postdeposicionales edafogénicos de carbonatación-recarbonatación por el movimiento coloidal de sales solubles en ambiente hidromórfico (Figura 4: 6), así como procesos de bioturbación de micro y meso fauna (Figura 4: 3).

La muestra de la Unidad III, tras ser cortada, limpiada y pulida, reveló una estructura interior evidentemente heterogénea que desaconsejaba intentar su da-

\begin{tabular}{|c|c|c|c|c|c|c|c|c|c|}
\hline Capas & Armaduras & Buriles & Raspadores & Truncaduras & $\begin{array}{c}\text { Retoque conti- } \\
\text { nuo lateral }\end{array}$ & Raclettes & $\begin{array}{c}\text { Muescas y } \\
\text { denticulados }\end{array}$ & $\begin{array}{c}\text { Fragmentos } \\
\text { retocados indet }\end{array}$ & \begin{tabular}{c} 
Totales \\
\hline SG
\end{tabular} \\
\hline & 1 & 7 & 7 & 0 & 0 & 0 & 2 & 0 & 17 \\
\hline HSN & 4 & 1 & 3 & 1 & 0 & 2 & 0 & 2 & 13 \\
\hline HSM & 2 & 0 & 4 & 1 & 1 & 1 & 0 & 0 & 9 \\
\hline $\mathbf{1}$ & 3 & 0 & 0 & 0 & 1 & 0 & 1 & 0 & 5 \\
\hline $\mathbf{2}$ & 1 & 0 & 1 & 0 & 3 & 1 & 0 & 0 & 6 \\
\hline $\mathbf{3}$ & 1 & 0 & 0 & 0 & 1 & 0 & 0 & 0 & 2 \\
\hline $\mathbf{4}$ & 0 & 0 & 0 & 0 & 0 & 0 & 0 & 0 & 0 \\
\hline $\mathbf{5}$ & 0 & 0 & 0 & 0 & 0 & 0 & 0 & 0 & 0 \\
\hline $\mathbf{6}$ & 0 & 0 & 0 & 0 & 0 & 0 & 0 & 0 & 0 \\
\hline $\mathbf{7}$ & 2 & 0 & 1 & 0 & 0 & 0 & 0 & 0 & 3 \\
\hline $\mathbf{8}$ & 0 & 0 & 1 & 0 & 0 & 0 & 0 & 0 & 1 \\
\hline TOTALES & $\mathbf{1 4}$ & $\mathbf{8}$ & $\mathbf{1 7}$ & $\mathbf{2}$ & $\mathbf{6}$ & $\mathbf{4}$ & $\mathbf{3}$ & $\mathbf{2}$ & $\mathbf{5}$ \\
\hline
\end{tabular}

Tabla 4: HC.VF, cuadrícula O4. Utillaje configurado. / HC · VF, grid O4. Lithic implements. 
tación. En la figura 2 se puede observar claramente la presencia de numerosos canales longitudinales y transversales atravesando el objeto, rellenados con deposiciones secundarias, posteriores a su formación. La movilización de uranio por acción del agua se encuentra especialmente favorecida en medios ricos en carbonatos y ambientes más alcalinos, que son los habituales para la formación de este tipo de rocas. De hecho, el carbonato puede actuar de quelante del uranio, y disolverlo fácilmente en condiciones anóxicas, e incluso solubilizar el U(IV) vía cambio de su estado de oxidación en condiciones oxidantes. Por ello, la presencia de estas estructuras en la roca analizada se considera indicador de existencia de intercambio de sales entre la roca y el medio, revelando una condición clara de sistema abierto. Por otro lado, el material se presenta con crecimientos masivos, no laminados, con un amplio rango de estructuras más o menos compactadas, con grietas en su interior y de color heterogéneo con distintos tonos marrones, que sugiere distintas condiciones de formación.

A partir de una muestra de carbón procedente de la última de las capas excavadas se obtuvo una datación por radiocarbono. El resultado es coherente con las conocidas para diversos niveles del Gravetiense regional: Malladetes, Cendres, Comte o Casa dels Moliners, entre otros. Hace unas décadas, el Solutrense era el tecnocomplejo más dinámico y reconocible en la región centro-meridional ibérica (Fullola, 1979). A finales del siglo XX, esta posición la ocupó el Magdaleniense (Aura Tortosa et al., 1995) y en los últimos años el Gravetiense está alcanzando una amplia dispersión (de la Peña, 2012; Villaverde et al., 2019; Zilhão, et al., 2017; Aura et al., 2013). El resultado de la datación radiocarbónica, la sitúa en el arranque de la segunda mitad del Gravetiense, sin que los datos industriales recuperados en HC-VF permitan profundizar en sus rasgos tecnotipológicos.

La posición topográfica de 04 en relación al Sector A (Fig. 1) y la cota de la propia muestra actualizan alguna de las preguntas planteadas por Davidson (1989) referenciadas anteriormente. Si nos guiamos por las características de los sedimentos y por la presencia/ ausencia de materiales arqueológicos resulta razonable concluir que los materiales de las capas 7-8 de 04 no coinciden con los descritos para las capas 7 y 8 de las cuadrículas 25 y 26, por poner un ejemplo. Tampoco el espesor de nuestros levantamientos coincide con los practicados en las excavaciones de 1968-1984 (Aparicio, 2003). La posición del nivel 0 durante estas excavaciones ha podido ser establecida basándonos en todas las comprobaciones posibles: las referencias incluidas en la memoria y los datos de campo. A partir de estas fuentes, sabemos que la cota de la datación de $\mathrm{O} 4$ se posiciona en una profundidad similar a la señalada para hojitas de dorso y escalenos (= ¿Magdaleniense?), e incluso de las primeras referencias de raclettes y microraederas (= ¿Badeguliense?). Por tan- to, el resultado radiocarbónico de la muestra de $\mathrm{O} 4$ es claramente más antiguo que la edad de los materiales con los que podría relacionarse, si nos basamos en la proyección de su plano horizontal con las cuadrículas cercanas a la pared-bóveda de la cavidad. Este desajuste puede ser explicado por el simple -y pronunciado- buzamiento del depósitos, compatible con las diferencias observadas entre las cuadrículas externas (O4) y las internas (Fig. 1C). No obstante, por la información obtenida hasta ahora parece razonable aplazar una valoración de estas cuestiones hasta que se disponga de los datos del corte sagital (TSS).

Se trata de preguntas abiertas que las industrias líticas no permiten discutir, pues el número de piezas líticas estudiadas es reducido y desigual. Su análisis indica que a partir de la capa 4, pero sobre todo en las últimas capas (7 y 8), se aprecia un incremento del módulo de anchura de las hojas $(<15 \mathrm{~mm}$ ) y, en general, una talla laminar más cuidada. En paralelo se constata una talla microlaminar para obtener los soportes de las armaduras que parece disociada de la talla laminar de mayor formato, debido a que no se aprecian evidencias sobre la continuidad laminar-microlaminar en la talla de los volúmenes, mientras que la producción de lascas queda registrada a partir de la identificación de un núcleo procedente de la capa 2. Los morfotipos retocados son escasos y los que podrían ser más diagnósticos se encuentran en los tramos superficiales. La asociación de morfotipos magdalenienses, badegulienses (raclettes) y solutrenses (base de hoja bifacial) se concentran en las capas más superficiales, hasta la capa 3 (Fig. 8). En las capas 4 a 6 no se identifican útiles configurados y en las 7 y 8 solo dos raspadores, dos armaduras y alguna pieza esquirlada, coincidiendo con el incremento de los productos laminares y también de sus módulos de anchura (Fig. 9).

Los materiales de las excavaciones realizadas entre 1969-1983 de las cuadrículas adyacentes no tienen una correlación fácil con estos datos. Las cuadrículas $9,8,7,6$ y 5 , más lo que se denominó inicialmente como Sector B (I23, I24 y I25) son tangentes a O4. La descripción de la industria lítica de estas cuadrículas y capas es genérica en la memoria: microrraspadores, raspadores, buriles, hojitas de dorso. Salvo una pieza "racletoide", en la capa 2 de la cuadrícula I23 (Aparicio, 2003: 270), no se menciona ningún morfotipo que pueda orientar sobre su adscripción industrial.

Como se puede observar, a la hora de ordenar y jerarquizar la información descrita hasta ahora cabe indicar que los datos microsedimentarios, radiocarbónicos, industriales y topográficos plantean varias cuestiones que afectan tanto a la disposición general del depósito como a la propia secuencia arqueo-estratigráfica de HC-VF. En el momento actual, no contamos con elementos suficientes para proponer una explicación completamente satisfactoria y por tanto se ha optado por valorar dos alternativas, pero asumiendo antes algunas de las observaciones planteadas hasta ahora. 

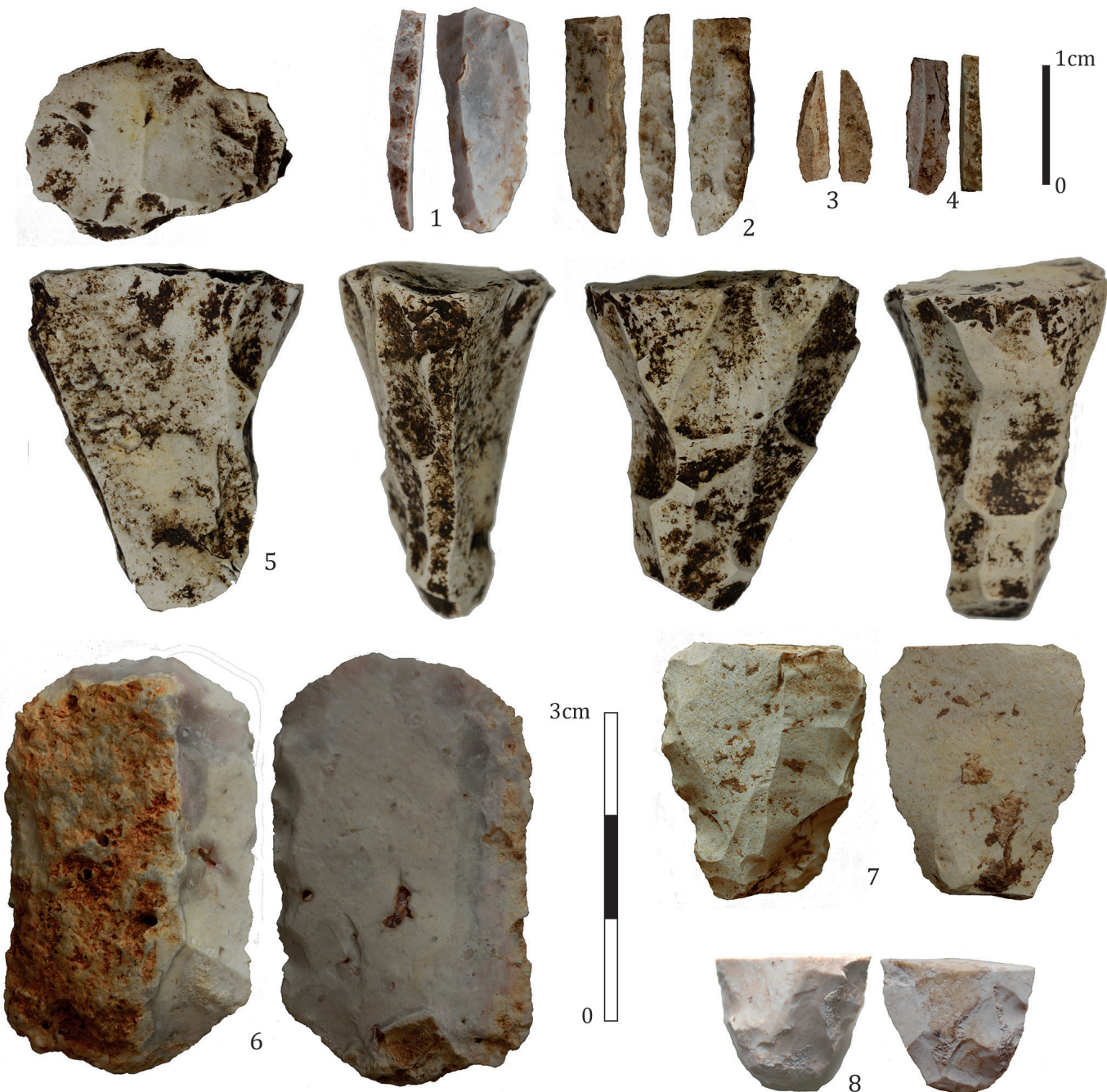

$3 \mathrm{~cm}$
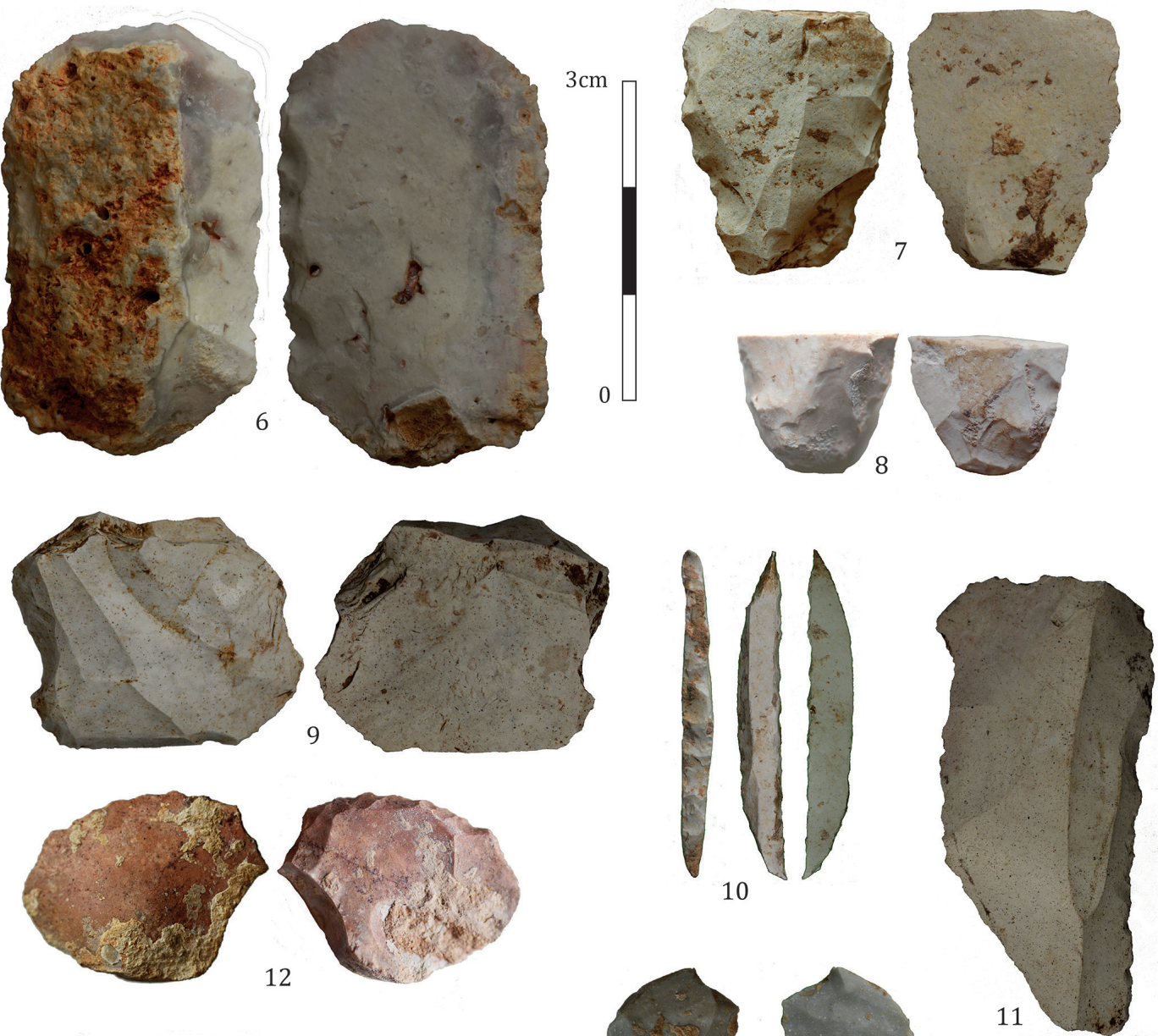

Fig.8. HC.VF, industria lítica de las capas superiores de la cuadrícula 04. 1-4: armaduras; 5 y 9: núcleos; 6: raspador; 7 y 11: hojas con retoques continuos; 8: base de hoja de laurel; 10: bipunta de dorso; 12: raclette; 13: ; 14: denticulado; (nivel hsn y hsm: $1-7,9$ y 11 capa 1: 14 ; capa 2: 10 12 y 13; capa 3: 8). Lithic industry from $\mathrm{O} 4$ upper layers. 1-4: backed bladelets; 5 and 9 : cores; 6: end-scraper; 7 and 11: blades with continuous retouch; 8 : solutrean laurel leaf foliate; 10: backed doublé point; 12: raclette; 13: sidescraper; 14: denticulate; (layers hsn and hsm: $1-7,9$ and 11 ; layer 1: 14; layer 2: 10,12-13; 


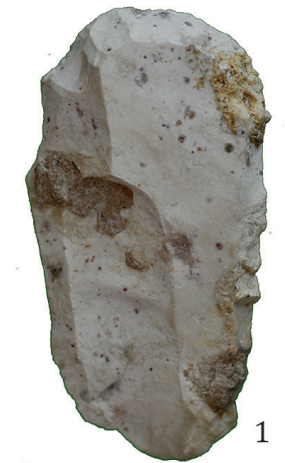

${ }^{3 \mathrm{~cm}}$
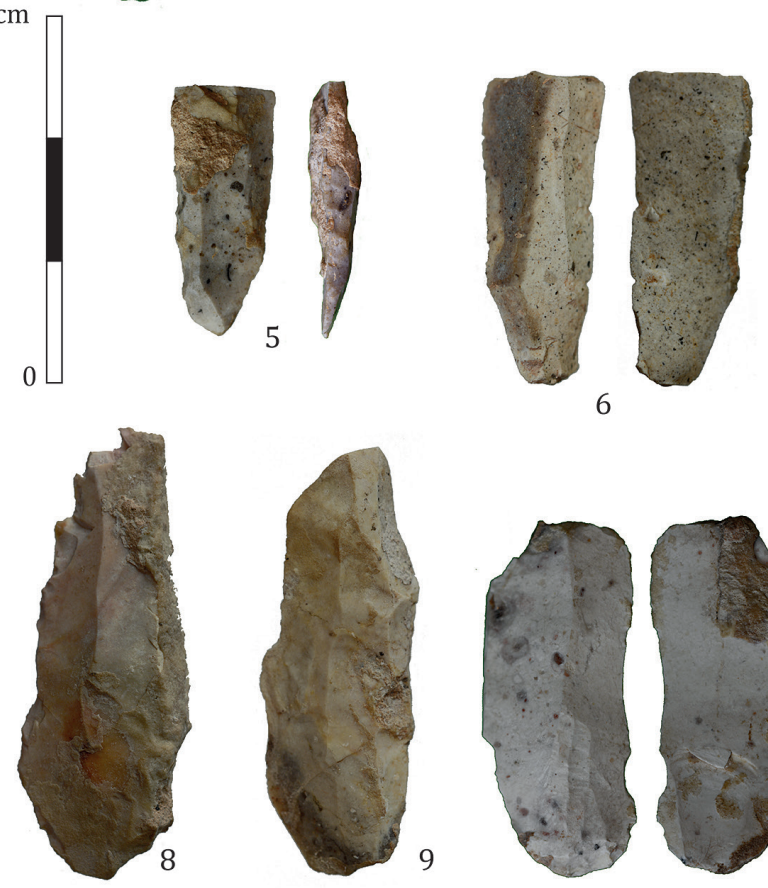

6

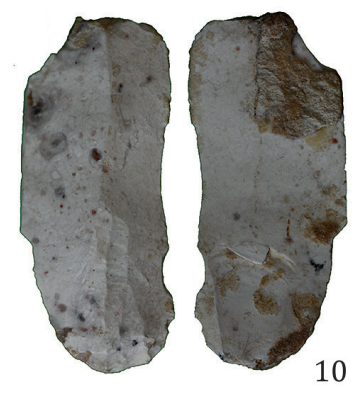

10
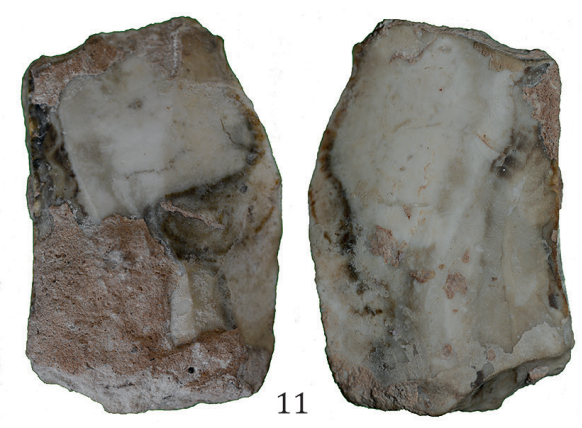

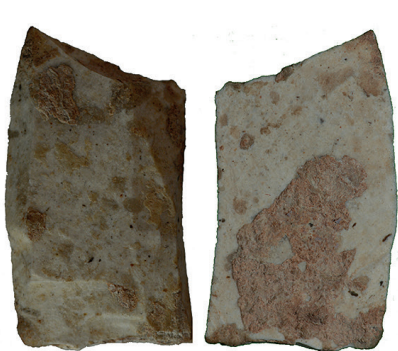

3
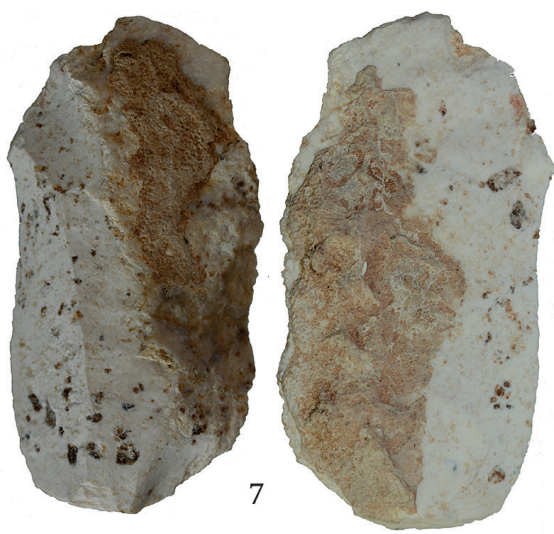

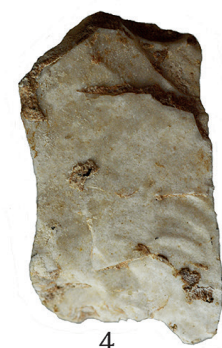

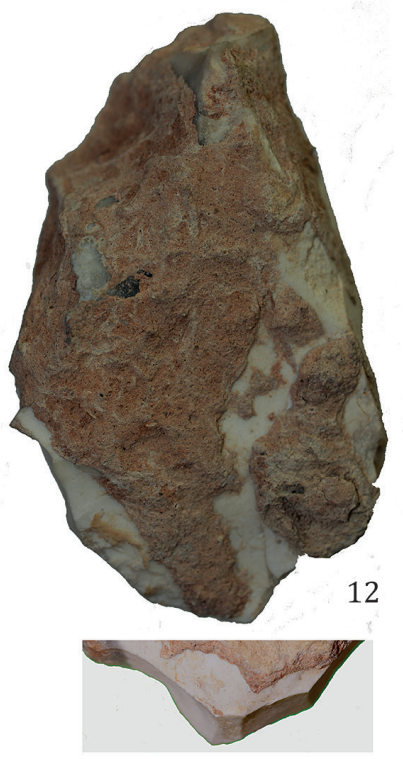
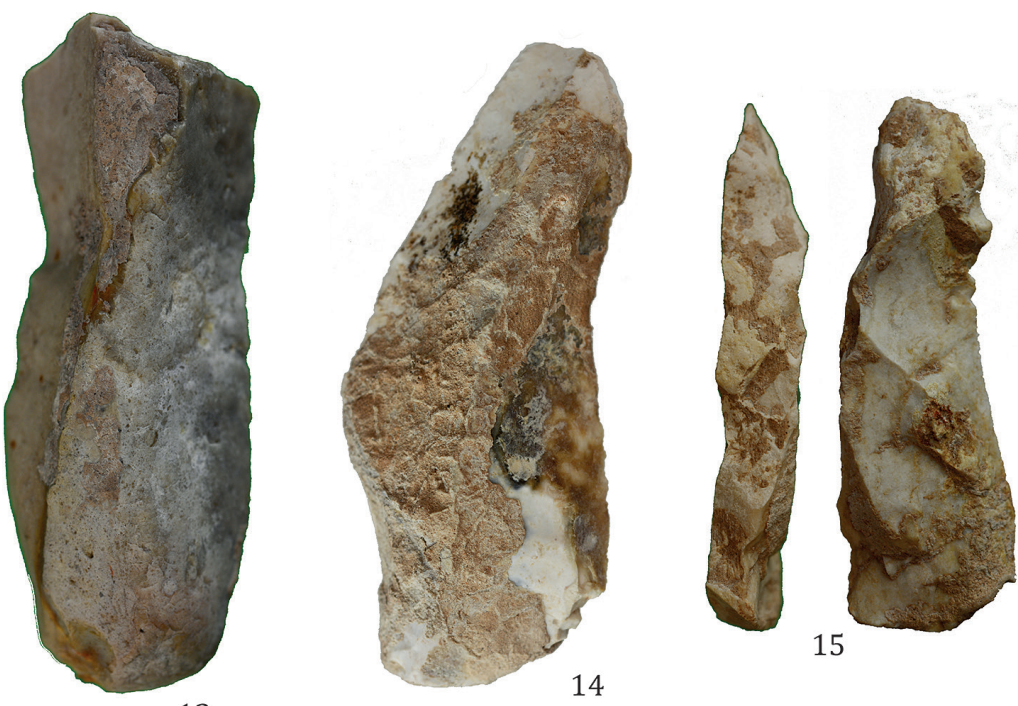

13

Fig.9. HC.VF, industria lítica de las capas inferiores de la cuadrícula 04. 1-2: raspadores; 3, 6, 7-11: hojas de diferentes módulos tipométricos; 4: pieza esquirlada; 5: hojita de dorso; 12-15: productos de acondicionamiento. (capa 6: 3, 4, 7; capa 7: 2, 5, 6; capa 8: 1, 8-15). / Lithic industry from O4 lower layers. 1-2: end-scrapers; 3,6,7-11: blades; 4: splintered piece; 5: backed bladelet; 12-15: manitenance products; (layer 6: 3, 4, 7; layer 7: 2,5,6; layer 8: 1, 8-15). 
- Las cuadrículas externas del sector A muestran una pobreza, incluso esterilidad completa, de materiales arqueológicos, según los datos extraídos de la memoria (Aparicio, 2003). En la cuadrícula 9 las capas por debajo de la 5 son estériles, y otro tanto ocurre en las cuadrículas 10, 17 y 18, sin materiales a partir de la capa 3.

- La textura y compactación del sedimento excavado en O4 no favorecen considerar la posibilidad de procesos de percolación de materia orgánica, más concretamente de restos de carbón. El material lítico y bioarqueológico obtenido hasta ahora de la Unidad III se encontraba cementado por las costras.

- La datación radiocarbónica debe ser discutida a partir de la estratigrafía y la seriación que el material arqueológico permiten, teniendo en cuenta la topografía del yacimiento.

Si aceptamos, al menos provisionalmente, estas asunciones como válidas, las alternativas de explicación deben focalizarse sobre el depósito arqueo-estratigráfico y sobre los resultados de la datación radiocarbónica, pues los materiales recuperados hasta ahora son genéricos.

\section{Alternativa $A$ :}

O4 debe ser valorado como un testigo de un depósito presolutrense en el límite externo del sector A (Fig. 10). En las cuadrículas de su mismo eje $(9,10,17$ y 18) se describe la presencia de materiales paleolíticos en los primeros 0,60 cm. Por debajo de estas cotas se describen grandes rocas, tierras endurecidas y la práctica ausencia de materiales líticos hasta alcanzar los 2-3m, según cuadrículas. Por su parte, en las cuadrículas 25-26 y siguientes se describen materiales paleolíticos desde las capas superiores de forma ininterrumpida, reconociéndose la sucesión de morfotipos ya señalada: magdalenienses, badegulienses y solutrenses.

Por tanto, la relación de los materiales, también de la datación, de $\mathrm{O} 4$ sólo es posible establecerla con los depósitos que contienen materiales supuestamente presolutrenses de las cuadrículas 25, 26, 35, 36 y 45 (Fig. 1C)

Esta situación hace viable que la cota de $\mathrm{O} 4$ y el resultado de la datación sea compatible con la existencia de un depósito afectado por el retroceso de pared-bóveda. Su conservación en las cuadrículas más externas pudo ser posible gracias a su sellado y a procesos de carbonatación.

\section{Alternativa B:}

Valora que la datación es discordante, más antigua, que los materiales que la acompañan. No obstante, por las características de la matriz y compactación, resulta difícil plantear percolaciones de materiales, que deberían ser de abajo a arriba en esta ocasión. Los materiales descritos en 04 serían magdalenienses, como los de las cuadrículas internas, y la datación incompatible.

Considerar que la fecha obtenida es más antigua que los materiales a los que se asocia tampoco tendría en cuenta que a techo de la muestra datada, en una matriz de materiales meteorizados, se encuentran morfotipos magdalenienses, badegulienses y solutrenses. Cabe suponer que su asociación es consecuencia de procesos de redeposición, cuya causalidad desconocemos ni tampoco el momento en que se activaron, pero compatible con un momento posterior a la edad proporcionada por la datación. Esta es la posición que ocupan en la secuencia estratigráfica conocida hasta

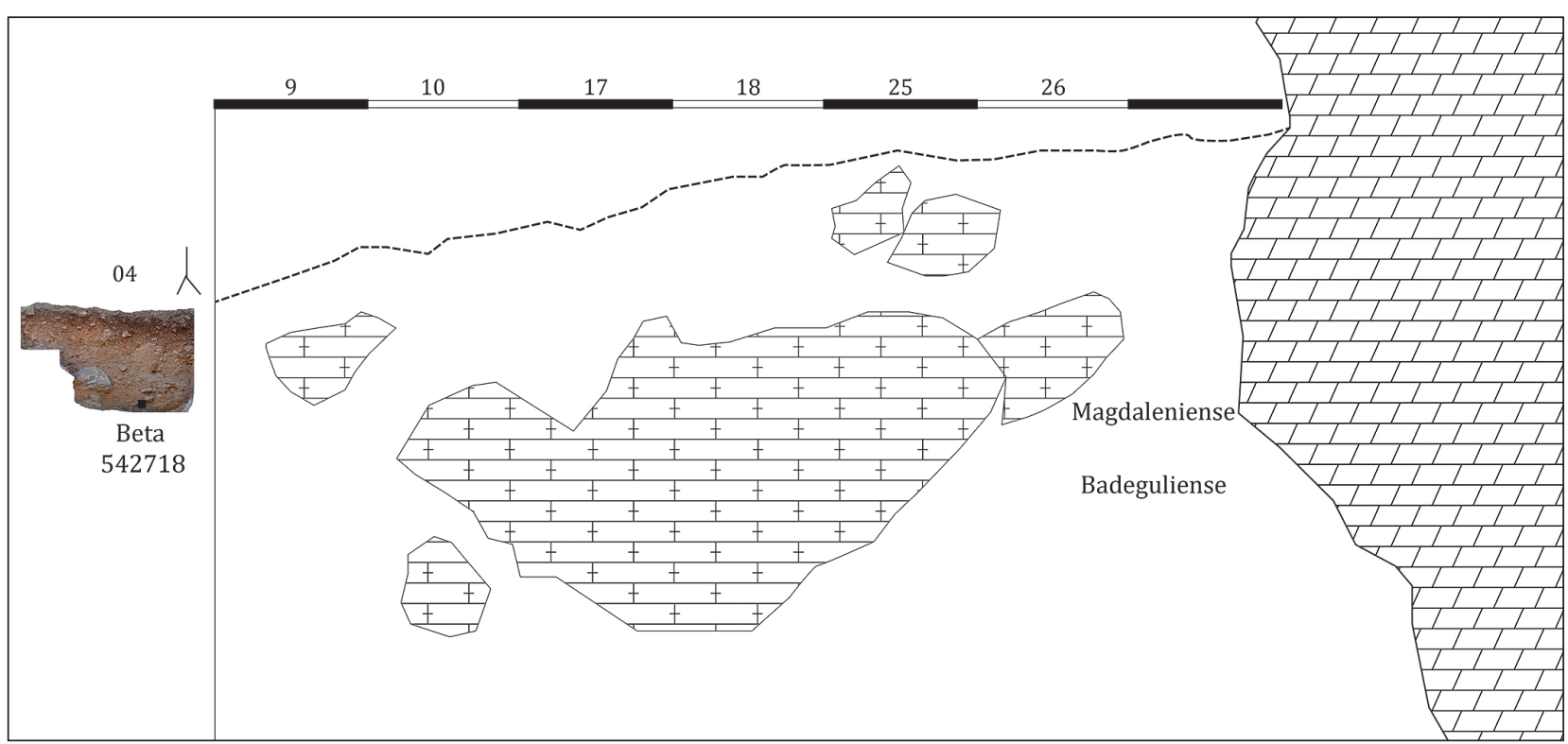

Fig.10. HC.VF. Situación de la datación AMS obtenida en $\mathrm{O} 4$ en relación con el corte y materiales arqueológicos del Sector A de las excavaciones 1968-84. / HC -VF. Situation of the AMS date obtained in $\mathrm{O} 4$ in relation to the section and the archaeological materials of Sector A of 1968-84 excavations. 
ahora. Además, si hacemos intervenir los materiales estudiados en $\mathrm{O} 4$, las producciones líticas de las capas 7-8 son laminares con una anchura y regularidad que está reconocida en momentos presolutrenses y, por tanto, la secuencia de materiales y este argumento tecnológico serían compatibles con el resultado de la datación.

Aceptar una u otra alternativa para responder a la cuestión sobre si en el yacimiento existen ocupaciones presolutrenses no es sencillo, sobre todo por nuestro conocimiento actual. La segunda, a partir de considerar una desconexión entre los materiales y la datación, se fundamenta en datos y argumentos más débiles, pero no es completamente descartable.

\section{CONCLUSIONES}

Los trabajos iniciados en HC-VF han permitido obtener los primeros datos y plantear un análisis, quizás cercano en algún momento a la especulación, sobre una secuencia que deberá ser contextualizada sobre bases geoarqueológicas, cronológicas y arqueológicas. A partir de la revisión cronoestratigráfica de su secuencia y materiales, confiamos en que el yacimiento se pueda incorporar a los temas de discusión abiertos en torno al Paleolítico superior de la Península Ibérica y del sur de Europa.

Se ha empezado a reconocer la complejidad de su estratigrafía y se ha realizado un análisis morfosedimentario puntual del sondeo abierto en el perímetro de las excavaciones Ilevadas a cabo entre 1969-1984. La muestra de una costra laminada que pretendimos analizar y datar aunaba un interés doble: la posibilidad de obtener una datacón directa y de contar con ciertas garantías sobre el sellado de los niveles situados a muro.

Se han estudiado las industrias líticas recuperadas, reconociendo que estaban orientadas a la obtención de productos laminares-microlaminares, identificando morfotipos postgravetienses en el tramo superficial. Por último, se ha podido obtener la primera datación radiocarbónica de este sondeo. Todos estos datos plantean nuevas bases de discusión sobre la existencia de ocupaciones presolutrenses en HC-VF y que hasta ahora estaban basadas en intuiciones orientadas por la posición de algunos morfotipos líticos.

No obstante, una datación no permite, por si misma, concluir que el yacimiento contiene ocupaciones gravetienses pero si obliga a pensar en la articulación general de lo que fue en su día un yacimiento paleolítico y actualmente es una enorme cala de $65 \mathrm{~m}^{2}$ y $9,5 \mathrm{~m}$ de profundidad. El sitio fue ocupado durante el Pleniglacial, el Tardiglaciar y, con dudas, quizás también en el Holoceno antiguo, aprovechando un entorno que sufrirá profundas transformaciones y al que, intencionadamente, no hemos prestado ninguna atención en este texto.

La primera conclusión es que HC-VF es un yacimiento complejo. Las diferencias entre las cuadrículas externas e internas cuestionan que la cronología y ma- teriales de la capa 8 de 04 sean sincrónicos, en términos arqueològicos, de los de la misma capa de la cuadrícula 26, por mencionar uno de los ejemplos citados. La discusión en torno a la datación y su posición topográfica indica que los episodios de colapso y los procesos de relleno pueden ser dinámicas decisivas a la hora de analizar la formación general del yacimiento y también su conservación.

\section{AGRADECIMIENTOS}

A Paloma Vidal Matutano, Yolanda Carrión Marco y Ricard Marlasca, por sus aportaciones en el estudio de los restos bioarqueológicos. Al Museu de Prehistòria de València y Servei d'Investigacó Prehistòria de la Diputació de València por retomar un proyecto de investigación sobre un yacimiento histórico y permitirnos el acceso a los materiales de las antiguas excavaciones. A l'Ajuntament de Cullera por su colaboración en las infraestructuras.

Este trabajo forma parte de los Proyectos Aico/2018/125 y 2020/97 de la Generalitat Valenciana, Direcció General de Ciència i Investigació, Conselleria d'Innovació, Universitats, Ciència i Societat Digital.

\section{BIBLIOGRAFIA}

Aparicio, J., Fletcher, D., 1969. Cueva prehistórica de "El Volcán del Faro" (Cullera, Valencia). XI Congreso Nacional de Arquelogía, 175-183. Zaragoza.

Aparicio, J., 1977. La Cueva del Volcán del Faro (Cullera, Valencia). Serie 50 Aniversario de la Fundación del SIP, Valencia.

Aparicio, J., 2003. El Paleomesolítico valenciano: Cova del Volcán del Faro: memoria de las excavaciones e inventario del material. Real Academia de Cultura Valenciana. Sección de Prehistoria y Arqueología, Valencia.

Aura Tortosa, J.E., 1988. La Cova del Parpalló y el Magdaleniense de facies ibérica o mediterráneo. Propuesta de sistematización de su cultura material: industria lítica y ósea. Universitat de València.

Aura Tortosa, J.E., 1995. El Magdaleniense mediterráneo: la Cova del Parpalló (Gandia, Valencia). Trabajos varios del Servicio de Investigación Prehistórica 91, Valencia.

Aura Tortosa, J.E., 2007. Badegouliens et Magdaléniens du versant méditerranéen espagnol. Bulletin de la Société préhistorique française 104, 809-824.

Aura Tortosa, J.E., Tiffagom M., Jordá J.F., Duarte E., Fernández De La Vega J., Santamaría D., Rasilla M. de la, Vadillo M., Pérez Ripoll M., 2012. The Solutrean-Magdalenian Transition: a view from Iberia. Quaternary International 272-273, 75-87.

Aura Tortosa, J.E., Jordá, J.F., Pérez, M., Badal, E., Avezuela, B., Morales, J.V., Tiffagom, M., Wood, R., Marlasca, R., 2013. El corredor costero meridional: los cazadores gravetienses de la Cueva de Nerja (Málaga, España). En: de las Heras, C., Lasheras, J.A., Arrizabalaga, A., Rasilla, M. (Eds.), Pensando el Gravetiense: nuevos datos para la región cantábrica en su contexto peninsular y pirenaico, 104-113. Ministerio de Educación, Cultura y Deporte, Madrid.

Bronk Ramsey, Ch., 2017. Radiocarbon 59, 1809-1833. 
Casabó, J., 2005. Paleolítico superior final y Epipaleolítico en la Comunidad Valenciana, Museu Arqueològic d'Alacant, Serie Mayor, Alicante.

Casabó, J., Boronat, J. de D., Carrión Marco, Y., Esquembre, M.A., Guillem, P.M., Martínez-Valle, R., Soler, B., Costa, P., Bolufer, J., 2016. New evidence of Palaeolithic rock art at the Cova del Comte (Pedreguer, Spain): results of the first surveys. Quaternary International 432, 25-40

Candy, I., Black, S., Sellwood, B. W., 2005. U-series isochron dating of immature and mature calcretes as a basis for constructing Quaternary landform chronologies for the Sorbas basin, southeast Spain. Quaternary Research 64(1), 100-111.

Cuerda Barceló, J., Gasull, L., 1971. Cova el Volcán del Faro de Cullera: fauna malacológica. MS en Museu de Prehistòria, SIP, València.

Cumberland, S.A., Douglas, G., Grice, K., Moreau, J.W., 2016. Uranium mobility in organic matter-rich sediments: A review of geological and geochemical processes. Earth-Science Reviews 159, 160-185.

Davidson, I., 1973. The fauna from la Cueva de Volcán del Faro (Cullera,Valencia). Archivo de Prehistoria Levantina 13, 7-15.

Davidson, I., 1976. Les Mallaetes and Mondúver: the economy of a human group in prehistoric Spain. In: Sieveking, G de G., Longworth, I.H., Wilson, K.E., Clarke, G., Problems in economic and social Archaeology. Ed. Duckworth, Londres.

Davidson, I., 1989. La Economía del Final del Paleolítico en la España oriental. Trabajos varios del Servicio de Investigación Prehistórica 85, València.

De la Peña, P., 2012. Sobre la unidad tecnológica del Gravetiense en la Península Ibérica: implicaciones para el conocimiento del Paleolítico superior inicial. Tesis de la Universidad Complutense de Madrid, Facultad de Geografía e Historia, Departamento de Prehistoria, Madrid.

Eastham, A., 1973. Birds from Cueva del Volcán del faro. MS inédito, fechado el 18-VIII-1973. Museu de Prehistòria, SIP. València [Citado por I. Davidson (1989)].

Fletcher, D., Aparicio, J., 1969. Bastón de mando procedente de Cullera (Valencia). Qüartar 20, 189-193.

Fortea, F.J., 1973. Los complejos microlaminares y geométricos de epipaleolítico mediterráneo español. Memoria del Seminario de Prehistoria y Arqueología 4, Universidad de Salamanca, Salamanca.

IGME (en línea) Mapa Geológico Continuo de España a escala 1/50.000, Continuous Geological map of Spain scale 1/50.000. Instituto Geológico Minero de España <http://igme.maps. arcgis. com/home/webmap/viewer.html?webmap=44df600f5c6241b59edb596f54388ae4> (accessed 25.05.2020).

Inizian, M.-L., Reduron, M., Roche, H., Tixier, J., 1995, Préhistoire de la pierre taillée 4 - Technologie de la pierre taillée. CNRS-Université Paris 10. Meudon-Nanterre.

Jorda Cerdá, F., 1949. Secuencia estratigráfica del Paleolítico levantino. In: Crónica del IV Congreso Arqueológico del Sudeste Español (Elche 1948), 104-110, Publicaciones de la Junta Municipal de Arqueología y del Museo de Cartagena, Cartagena.

Miret Estruch, C., Carrión Marco, Y., Hortelano Piqueras, L., Jardón Giner, P., Ruiz Pérez, J.M., de Wit, H.M., 2016. Casa dels Moliners (Castell de Castells, Marina Alta, Alacant). Un jaciment a l'aire lliure del Paleolític superior en el Pla de Petracos. Archivo de Prehistoria Levantina 31, 27 - 60.
Pelegrin, J., 2000. Les techniques de débitage laminaire au Tardiglaciaire: critères de diagnose et qualques réflexions. In: Valentin, B., Bodu, P., Christensen, M., (Dir.), L'Europe Centrale et septentrionale au Tardiglaciaire, Table-ronde de $\mathrm{Ne}$ mours, 13-16 mai 1997, 73-86. Mémoires de Préhistoire d'lle de France.

Pericot, L., 1942. La Cova del Parpalló (Gandía,Valencia). Publicaciones C.S.I.C., Instituto Diego Velázquez, Madrid.

Perlès, C., 1991, Économie de la màtiere premières et économie du débitage: deux conceptions opposées? In: XI Rencontres Internationales, d'Archeologie et d'Historie d'Antibes. 25 ans d'études technologiques en préhistoire. Actes des rencontres 1990, 35-45. Éditions APDCA, Juan-les-Pins

Reimer, P.J., Bard, E., Bayliss, A., Beck, J.W., Blackwell, P.G., Bronk Ramsey, C., Grootes, P.M., Guilderson, T.P., Haflidason, H., Hajdas, I., Hatt_Z, C., Heaton, T.J., Hoffmann, D.L., Hogg, A.G., Hughen, K.A., Kaiser, K.F., Kromer, B., Manning, S.W., Niu, M., Reimer, R.W., Richards, D.A., Scott, E.M., Southon, J.R., Staff, R.A., Turney, C.S.M., Van Der Plicht, J., 2013. IntCal13 and Marine13 radiocarbon Age calibration curves 0-50,000 Years cal BP. Radiocarbon 55(4), 1869-1887.

Sarrión Montañana, I., 1984. Nota preliminar de los yacimientos pleistocénicos en la Ribera Baixa, València. Cuadernos de Geografía 35, 163-174.

Sarrión Montañana, I., 2008. Presencia de Homo en el Pleistoceno inferior y medio valenciano. Archivo de Prehistoria Levantina XXVII, 9-23.

Soler, B., Tiffagom, M; Aura, J.E., 2013. La Cova del Volcán del Faro (Cullera) més preguntes que respostes. Primeres dades sobre els elements ornamentals. In: Sanchis Serra, A., Pascual Benito, J.LI. (Eds.), Animals i arqueología hui. I Jornades d'arqueozoologia, 159-180. Museu de Prehistòria de València, València.

Sonneville-Bordes, D., Perrot, J., 1954. Lexique typologique du Paléolithique supérieur. Outillage lithique I, grattoirs, II, outils solutréens". Bulletin de la Société préhistorique française 51(78), 327-335

Sonneville-Bordes, D. Perrot, J., 1955. Lexique typologique du Paléolithique supérieur. Outillage lithique III, outils composites-perçoirs. Bulletin de la Société préhistorique française 52(1-2), 76-80.

Sonneville-Bordes, D. Perrot, J., 1956a. Lexique typologique du Paléolithique supérieur. Outillage lithique IV, Burins. Bulletin de la Société préhistorique française 53(7-8), 408-413.

Sonneville-Bordes, D. Perrot, J., 1956b. Lexique typologique du Paléolithique supérieur. Outillage lithique (suite et fin). Bulletin de la Société préhistorique française 53(7-8), 547-559.

Sopeña, A., De Vicente, G., 2004. Cordilleras Ibérica y Costero-Catalana. Rasgos generales. In: Vera, J.A. (Ed.), Geología de España, 467-470. Sociedad Geológica de España e Instituto Geológico y Minero de España, Madrid.

Villaverde, V., Real, C., Roman, D., María Albert, R., Badal, E., Bel, M.A., Bergada, M., De Oliveira, P., Esteban, I., Martínez-Alfaro, M., Martínez, C.M., Pérez, M., Eixea, A., Perez-Ripoll, M., 2019. The early Upper Palaeolithic of Cova de les Cendres (Alicante, Spain). Quaternary International 515, 92-194. https://doi.org/10.1016/j.quaint.2017.11.051

Zilhão, J., Anesin, D., Aubry, T., Badal, E., Cabanes, D., Kehl, M., Klasen, N., Lucena, A., Martín-Lerma, I., Martínez, S., Matias, $H ., 2017$. Precise dating of the middle to upper paleolithic transition in Murcia (Spain) supports late Neandertal persistence in Iberia. Heliyon 3, https://doi.org/10.1016/j.heliyon.2017.e00435. 
